\title{
Market-Oriented Procurement Planning Leading to a Higher Service Level and Cost Optimization
}

\author{
Sergio Gallego-García *(D) and Manuel García-García \\ Department of Construction and Fabrication Engineering, UNED, 28015 Madrid, Spain; mggarcia@ind.uned.es \\ * Correspondence: sgallego118@alumno.uned.es; Tel.:+34-682-880-591
}

Received: 1 November 2020; Accepted: 3 December 2020; Published: 6 December 2020

Featured Application: Optimization of inventory management for managers considering demand forecasting, procurement strategies, and different product lifecycles.

\begin{abstract}
The current global market situation pursues high adaptability, but why? Complexity due to mass customization is greater than ever. Globalization is no longer a theory but a fact that makes disruptions in the globalized supply chain a major risk for operations. In this context, customers demand novelty and unique experiences. These are the main drivers for market success. Therefore, existing products are now in continuous states of change with shortened product lifecycles. The purpose of this article is to analyze the impact of new market entries and product changes along the lifecycle as well as supply chain disruptions in supplier inventory levels. The goal is to minimize costs by achieving a given service level with a market-oriented procurement planning model. The model pursues minimizing the time needed to align the system with the market and, therefore, the adaptability of the system. The research compares classical inventory management models with the new proposed approach by means of simulation with the system dynamics methodology. The results show how the proposed model increased the delivery service level, reduced inventory costs, and increased the utilization of resources due to lower demand uncertainty. Therefore, the developed model is able to plan the inventory supply with a low risk of stock outages. The conclusion proposes a differentiated forecasting and inventory strategy depending on the product lifecycle stage. The developed market-oriented procurement planning model provides guidance for inventory managers regarding how to optimize their operations as an opportunity within the fourth industrial revolution to develop information technology (IT) systems to gather and utilize demand and inventory data with real-time efficiency.
\end{abstract}

Keywords: demand forecasting; product lifecycle; market changes; inventory planning; inventory cost; service level

\section{Introduction}

Man has dealt with inventory issues since we first began to utilize the resources of the planet [1]. The first mathematical approach for inventory planning was the economic lot size or economic order quantity (EOQ) model, performed by Harris in the 1910s [2]. Although the EOQ model was developed, it was not until the 1950s and 1960s when other major advances were realized to satisfy the needs of logistics, such as the consideration of surplus, shortage, and ordering costs, to determine inventory parameters [1]. Computerized forecasting and inventory control were initiated in the 1960s and 1970s [3]. Since the 1980s, a great effort has been made to develop inventory planning software solutions with the goals of reducing operating costs and working capital. However, in the daily business of most manufacturers in process industries, inventory planning is still driven by "manual" 
spreadsheet databases [4]. In addition, the EOQ model after one century is still analyzed and extended by researchers as well as used in practice [1].

Multiple models have already been developed by several authors on EOQ and economic production quantity (EPQ) for time-dependent demand, as well as models for stock-dependent demand [5]. Most of the developed models consider the demand of an item as an infinite parameter with product specifications that do not change over time [5]. In contrast, as markets became more complex, inventory management also became more complex [6], and market conditions began to change more quickly than researchers could respond [1]. Technology has led to rapid changes in product specifications leading to a high product demand volatility in a finite lifecycle [1]. As product lifecycles become shorter, the randomness of the demand increases [7]. As a result, most managers decide on inventory planning with a certain level of demand uncertainty.

In this context, many models have been developed to deal with uncertainty and to determine the optimal inventory policy [8]. However, most inventory models are related to the classical cost analysis approach with uncertain input data accuracy [1]. The cause of uncertainty can be the environment, such as demand uncertainty [8] or disasters, such as replenishment times or information delay on inventory levels. Storage holding costs in metropolitan areas are steadily increasing [5], leading to high pressure for stock optimization and to an increased risk for stockouts in normally well-populated areas of suppliers. Therefore, how to balance the stock-holding strategy versus the optimization of costs is a key decision for managers.

The need to respond to demand uncertainty is clear. Epidemic crises, product changes, and deviations in replenishment time can lead to stockouts and a high level of stocks required to provide a given service level. People affected by the potential lack of supplies are at great risk [9] as occurred with the COVID-19 global crisis when companies speculated with the demand offer, reducing it to increase margins due to the customer demand. By doing so, the purpose of a company to provide goods or services to society is not given. It is likely that further theoretical developments will be required and that there may be a need to develop methods that will determine inventory levels based on measures other than cost. Additionally, using cost minimization as a performance measure is unlikely to provide enough importance to meet users' and society's requirements. Generalizing to consider models in terms of the utility may be intellectually satisfying but leads to equally difficult problems of measurement [1].

COVID-19 had significant economic consequences globally [9]. This situation demonstrated the future risks and the current fragility of global healthcare infrastructure, such as a lack of medical resources and equipment [10]. The consequences have included production stops due to the lack of raw materials, while other producers had to decrease or shut off production because the finished products could not be shipped abroad. Therefore, there is an urgent practical need to increase manufacturing adaptability to be capable of reacting to unpredicted events, such as COVID-19.

In this context, Industry 4.0, with cloud manufacturing, the Internet of things (IoT), big data analytics, and digital twins, can improve the performance in these scenarios [11]. Recent research pointed to new opportunities for reducing disruption risks using data-driven approaches, and the analyses of the COVID-19 evolution provide significant evidence for the urgent needs of supply chain digital twins [12]. Simulation software can help to solve manufacturing challenges, such as the impact of investment and inventory planning in applying lean manufacturing techniques, and Industry 4.0 approaches, such as the Industrial Internet of things for better inventory management [13]

Based on the arguments exposed, the objective of the research paper is to develop a conceptual model of responses to the need to improve inventory management when facing highly uncertain demand [14] to provide supplier reaction time to changes, stock optimization for a required service level as a guideline for managers, as well as to provide a real service to humanity [14]. Some of the above-mentioned situations will depend on a specific event with an unknown probability and 
unknown timing, leading to high-risk levels and consequences [1] for society and organizations, for instance, COVID-19 or new market-entries from competitors.

\section{Materials and Methods}

\subsection{Methodological Approach}

Cybernetics deals with all forms of behavior insofar as they are regular, determinate, or reproducible. As a result, it is concerned with what a system does [15]. Due to the seven general principles of cybernetics [16], the use of cybernetics for developing the conceptual model was chosen, including the:

- $\quad$ system perspective,

- control loops,

- synergy,

- learning/lifecycle,

- $\quad$ sizing of the variety,

- Ashby's law of the variety requirement, and

- modeling.

Company cybernetics can be defined as meta-science with a theoretical approach that transfers the general methods and results of cybernetics related to the functional description of dynamic systems to be used to model the "company" as a system [17]. Cybernetics provides the basis for creating a management model for any viable system [18]. This is due to two reasons: First, it gives a vocabulary and a group of terms that can be used to represent most systems. This common language makes it possible for new developments in one area to be used in others. These concepts are relational; thus, they allow us to formally analyze and model different abstract properties of systems and their dynamics [19]. Second, cybernetics offers a method for dealing with highly complex systems, in which the complexity is too important to be ignored [15].

In the theoretical-cybernetic approach of a system, organizations are understood as open, dynamic and complex systems, which are subject to permanent changes and their own goal-oriented dynamics [20].

The cybernetic model will be implemented through simulation. There are three basic steps to perform a simulation: preparation, execution, and evaluation. In preparation, the objectives of the simulation and the relevant indicators of the simulation models should be defined. The execution process requires an abstraction of the actual or planned system to create a conceptual model. This conceptual model is transformed into a formal model that must be implemented in a feasible model. Parallel to this process, the input data that would feed the simulation in a certain configuration must be acquired and prepared. Then, the simulation of the different scenarios can be carried out and analyzed. The results are then interpreted according to the objectives and relevant performance indicators. In the end, this interpretation is used as a guide to change the actual or planned system [21].

Simulation models have been actively applied in the supply chain context. The main objectives are to generate knowledge of the supply chain, development, and validation of improvements using "what would happen if" analysis and quantification of the benefits of decision support at the level of strategic decision-making [22]. On the other hand, they allow us to evaluate possible scenarios before implementing a plan. This enables companies to make better planning decisions due to the additional information provided by the simulation. Therefore, the development of supply chain management simulation models has become a necessity [23]. The objectives of a simulation are, among others, the assurance of the methodology, as well as the planning, management, and control of the flows of people, materials, energy, and information [24].

The different simulation modeling approaches can be classified into discrete events, agent-based, system dynamics, and dynamic systems [25]. In this research paper, systems dynamics modeling is 
used due to its tactical-strategic level characteristic in which a high level of abstraction is required. In addition, the model would be classified as a continuous, stochastic, dynamic, and open system based on systems theory, and the following systems can be differentiated [26].

The system dynamics methodology offers two basic elements, causal loop diagrams and stock and flow diagrams, for the dynamic modeling of systems. It is a cybernetic methodology derived from the methods of control theory, descriptive decision theory, and various simulation techniques [27]. The application of system dynamics for the integral management of supplies makes sense as the cause-effect relationships show the interrelationships between the elements of the system and help to evaluate the influences of the different decisions in the global system.

The first application of system dynamics to a supply chain was made by Forrester and consisted of a theoretical supply chain made up of four levels: retail, wholesaler, distributor, and manufacturing. Forrester observed how a small change in the pattern of a customer's demand amplified the demand across the SC. This amplification of demand, which further increases the demand of the end customer, is known as the bullwhip or Forrester effect and can be used to measure the efficiency of the supply chain [22].

In the literature, the common assumptions are demand backlogging, linear cost functions, infinite capacity, constant delivery times, and a stationary stochastic demand. Logically, the common goals to reach were to minimize inventory retention costs under the condition to achieve a certain level of service for end customers [28]. The use of system dynamics for modeling supply chain management has reemerged in recent years after a long, stagnant period. The current research is focused on inventory management, supply chain process design and integration, time compression, demand amplification, and international supply chain management [29].

Bonney and Jaber [1] suggested that the identification of what we do and do not know over the product lifecycle will determine the focus of future research for inventory planning. In this paper, we focus on inventory planning, procurement policies, and demand planning using different elements from a literature review of the previous topics as well as cybernetics and system dynamics:

- Literature research on supply chain management, demand planning, inventory planning, procurement strategies, and economic analysis considering investments and costs.

- The development of a conceptual model as a management framework for decision-making for managerial positions within existing companies.

- The design of a case study for the automotive industry to test the conceptual model.

- The use of Vensim is a simulation program to apply the case study. Simulation allows companies to assess how and when it is better to make decisions. Therefore, these analyses can help to discover if certain decisions are wise or not acting as a decision-supporting tool [30].

- A comparison of the conceptual model versus other inventory planning models in different demand scenarios based on demand lifecycle patterns extracted from the literature with elements for lifecycle consideration.

\subsection{Delimitation of the Research Work}

Among the managerial challenges, the problem of inventory management is one of the most relevant and requires efficient solutions knowing that there is no one-fits-all approach suitable to all firms [31]. Inventory management is a key issue in supply chain management. The importance of inventory management in industrial applications derives from the effect of stockouts in customer satisfaction and of stocks in the economic balance of organizations. In addition, the value of U.S. inventories was estimated to be over USD 1707 billion in December 2013. Therefore, the potential savings from efficient inventory management offer great potential. Classical models for inventory management with uncertain demand include continuous-review policies and periodic-review policies. Classical models have one main advantage in that they are easy to implement. Therefore, they are optimal for simple inventory management cases. However, the complexity of supply chains limits 
the suitability of the classical models for inventory management due to capacity constraints and the variety of sources of uncertainty [32].

The comparison of different inventory replenishment policies can improve the level of customer service and reduce the inventory cost without requiring further resources [33]. Many inventory management studies investigated the inventory challenge as an isolated problem. However, decision-making in production, inventory, and supply chain management is essentially a problem of matching the diversity of external and internal factors of the organization [34]. Matching supply and demand is particularly challenging when the supply must be chosen before observing demand and when the demand is uncertain [34]. Inventory inaccuracy is prevalent in many industries and supply chains. Internet of things (IoT) and radio frequency identification (RFID) were identified as an effective potential solution to inventory inaccuracy by providing transparency in relation to inventory information [35].

Modeling is an important tool for investigating complex problems, such as the interaction between stock levels and the environment. Models that use only a few variables can indicate whether those variables have a positive or negative influence, and, by doing so, may broadly show the influence that they may have in isolation and help to identify variables that require a closer analysis [1]. However, due to system complexity, models optimizing one metric will, in general, not perform well when trying to optimize another indicator, such as cost. For these reasons, it is advantageous to perform 'total' simulations and assess the performance against many different important indicators, such as cost, return on investment, service level, inventory turnover, and labor requirements [1].

In this context, our research pursues this goal to provide a 'total' simulation with multiple options and parameters that provide a global evaluation and support tool for managers and planning employees dealing with challenges of demand, inventory, and procurement planning in all kinds of manufacturing companies. Within the software, various simulation models can be derived. For the results, three are selected, two based on literature and one developed based on the methodology exposed, named the market-oriented procurement planning model. The models are tested for a Tier 1 and an automotive manufacturer. The simulation case study assesses the performance of these three simulation models when dealing with five different demand scenarios. The patterns of the demand scenarios are extracted from the literature. By doing so, the different procurement policies can be tested in all potential lifecycle scenarios.

As a result, the research provides a framework for managers to design models, simulations, or tools of different complexity levels for planning purposes, considering a set of integrated key indicators. This work also proves the conceptual model with the case study and the simulation results.

\section{Design of the Conceptual and Simulation Models}

\subsection{Conceptual Model Development Based on System Theory and Statistics}

The conceptual model developed is based on:

- Brown [36]: "The quantitative study of the operation is made by statistical analysis of operational data to predict the outcome of similar conditions". Therefore, random data series are created for demand based on the demand values of past periods by reproducing "similar conditions". Then, based on this generated demand, a prediction of the future forecast uncertainty or error is obtained for various forecast proposals. The forecast proposals are calculated using different forecasting methods. Finally, based on criteria, such as the forecast uncertainty, the conceptual model decides whether to change to another forecasting method in order to reduce risk due to the existing or future uncertainty.

- System theory and cybernetics: from the historical development point of view, cybernetics can be considered as part of the system theory. Both sciences deal essentially with the same subject, so they can be difficult to separate from each other. However, the focus of system theory is on the development of systems, whereas cybernetics explores the control and operation of 
systems [37]. In this context, cybernetics is used as a basis for the conceptual model, as shown in Figure 1. In the beginning, based on a set of goals defined by the observer as an interactive agent, a forecasting method is selected. Then, the forecast of future demand is the input for the inventory and procurement planning. Later, the results are obtained, and, by comparing them with the goals, a self-optimization is performed by deciding to maintain or change the forecasting method, the inventory safety factors, and the order release point as well as the procurement policy to be applied. Finally, by doing so, the system converges to a defined set of goals with a feedback control loop each period or planning period.

- System dynamics (SD): This is a natural modeling tool for inventory planning due to its nature that focuses on stocks and flows [3]. It is applied to simulating the conceptual model. SD is a rigorous method for the qualitative description of exploring supply chains. It facilitates modeling and qualitative simulation analysis to design and control the supply chain structure [22]. SD can, should, and will be further used to improve supply chain management practice [28].

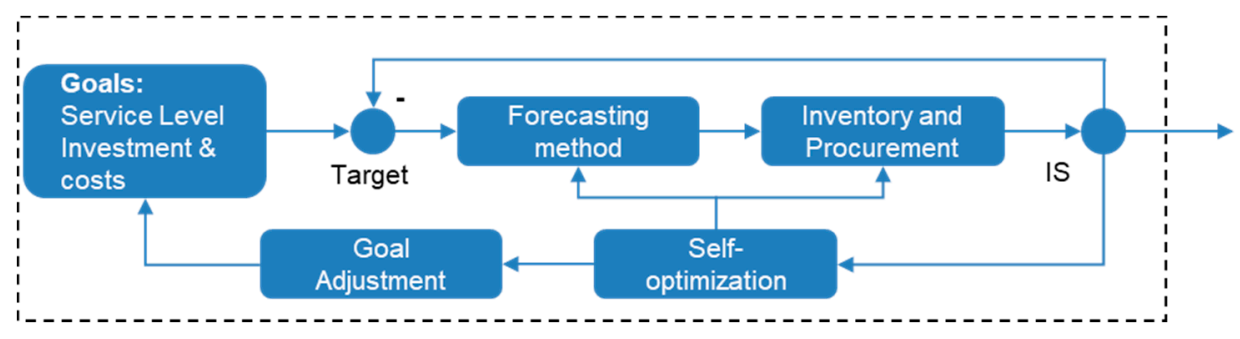

Figure 1. Cybernetics model for a market-oriented procurement (own elaboration based on [38] (p. 751)).

The market-oriented procurement planning model was named based on market-oriented organizations that have the following characteristics [39]:

1. Put the customer first.

2. Generate, analyze, and respond to market changes.

3. The capability to use resources efficiently to produce premium customer value.

This approach requires transparency and data sharing between actors in the supply chain to improve the customer service level while minimizing inventory management costs. The conceptual model is based on the following Figure 2. Demand planning depends on historical data and on the forecasting methods available and the one selected to be used. With the difference between real and forecast values, the forecast error is obtained. Based on the forecast values and the forecast error, the safety factor, $\mathrm{k}$ and the order release date for procurement orders are set for a defined service level. The procurement policy is determined based on the inputs from demand planning and inventory planning when considering the current delivery backlogs and the selected procurement policy. The procurement policy is selected as influenced by the type of product and the type and stage of the product lifecycle. Finally, procurement planning using a defined policy initiates the procurement of products by placing procurement orders. When the products arrive, the inventory management conceptual model finishes and repeats continuously. 


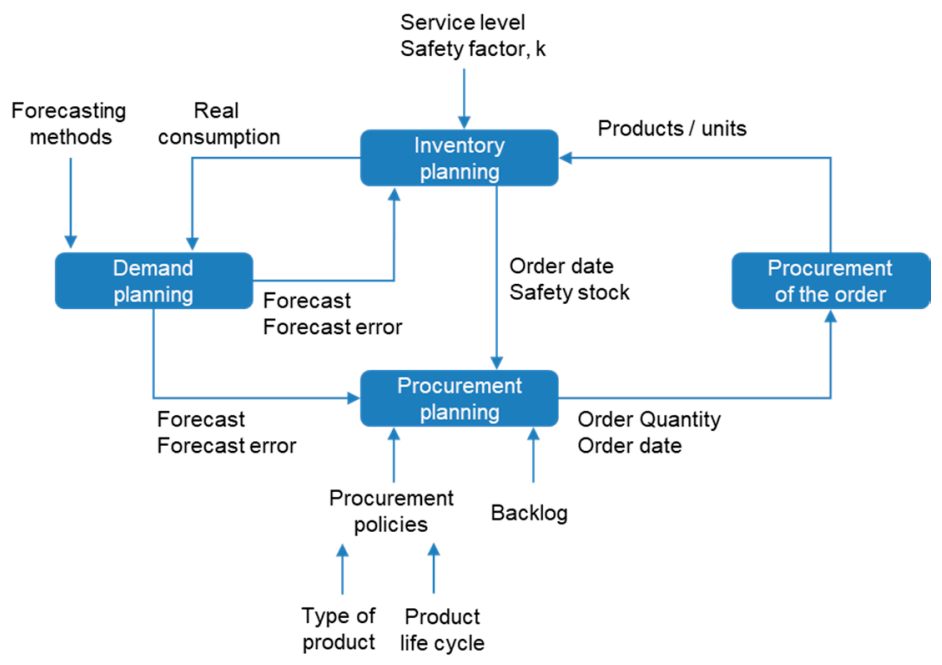

Figure 2. Conceptual framework for a market-oriented procurement (own elaboration).

The planning horizons are divided in analogy to the enterprise resource planning (ERP) systems structure [40]. Planning horizons of the cybernetics model for inventory management and related decisions are described in Table 1:

- Long-term planning horizon: in this planning horizon, decisions for increasing storage or production capacities can be taken. New locations can also be opened to increase capacities or shorten replenishment times. In the long-term, the model can decide to increase the service level goals and, therefore, the safety factor for the inventory levels.

- Medium-term planning horizon: The model decides on the production level as well as the level and conditions for employees on a monthly basis. In this planning horizon, the forecasting methods and procurement policies can change to be aligned or adjusted to a certain set of goals.

- Short-term planning horizon: it considers one week as the smallest period of the model in which changes can take place. In this planning horizon, parameters within the different planning method changes and variability of personnel can be performed to adapt production and inventories to the customer demand.

Table 1. Planning decisions in the market-oriented procurement model (own elaboration).

\begin{tabular}{|c|c|c|c|c|}
\hline No. & Area & $\begin{array}{l}\text { Short-Term Planning } \\
\text { (1 Week-1 Month) }\end{array}$ & $\begin{array}{l}\text { Medium-Term Planning } \\
\text { (1-3 Months) }\end{array}$ & $\begin{array}{l}\text { Long-Term Planning } \\
\text { (3 Months- } 1 \text { or More Years) }\end{array}$ \\
\hline 1 & $\begin{array}{l}\text { Demand } \\
\text { planning }\end{array}$ & Forecasting Parameters & $\begin{array}{l}\text { Forecasting method changes } \\
\text { based on forecast accuracy }\end{array}$ & $\begin{array}{l}\text { Forecasting methods } \\
\text { definition and random } \\
\text { number generation } \\
\text { methodology }\end{array}$ \\
\hline 2 & $\begin{array}{l}\text { Inventory } \\
\text { planning }\end{array}$ & $\begin{array}{c}\text { Days between orders for } \\
\text { economic order quantity } \\
\text { (EOQ) } \\
\text { Reorder point }\end{array}$ & $\begin{array}{l}\text { Procurement policy changes } \\
\text { based on the variation } \\
\text { coefficient }\end{array}$ & $\begin{array}{l}\text { Service level goal, safety } \\
\text { stock, safety factor }\end{array}$ \\
\hline 3 & $\begin{array}{l}\text { Procurement } \\
\text { planning }\end{array}$ & $\begin{array}{l}\text { EOQ quantity calculation } \\
\text { Target level adjustment }\end{array}$ & $\begin{array}{c}\text { Procurement policy changes } \\
\text { based on the variation } \\
\text { coefficient }\end{array}$ & $\begin{array}{l}\text { Procurement policies } \\
\text { available for } \\
\text { decision-making } \\
\end{array}$ \\
\hline 4 & $\begin{array}{l}\text { Organizational } \\
\text { Decisions }\end{array}$ & $\begin{array}{c}\text { Employees flexibility of } 10 \% \\
\text { based on weekly forecasts }\end{array}$ & $\begin{array}{l}\text { Production plan based on } \\
\text { monthly forecasts }\end{array}$ & $\begin{array}{l}\text { Working shifts based on } \\
\text { quarter forecasts }\end{array}$ \\
\hline 5 & $\begin{array}{l}\text { Investment-Risk } \\
\text { Strategy }\end{array}$ & No decision & No decision & $\begin{array}{c}\text { Open new warehouse } \\
\text { (increase of storage capacity) } \\
\text { Increase production } \\
\text { capacities }\end{array}$ \\
\hline
\end{tabular}




\subsection{Demand Planning and Forecasting Theory}

The purpose of demand planning is to improve the decisions that affect demand accuracy [41]. The main task is to calculate the future demand, and this comprises the selection of a specific forecasting method and its parameters [42]. The typical demand patterns are stationary, seasonal, trend, and sporadic [43]. There are three methods in requirement planning: demand-driven or deterministic, stochastic, and heuristic [42]. Deterministic demand planning assumes that when defining the demand planning, there is knowledge regarding the future, and this cannot be claimed as given without contradiction [43]. As an alternative, the consumption-oriented demand planning can be used by applying stochastic methods using the known historic consumption [43]. Stochastic methods determine the expected demand with the support of statistical forecast processes, while heuristic methods define the demand forecast based on subjective estimations of the planner [44].

In the model developed, we applied stochastic methods for demand planning as they can be applied for all typologies of inventories, even for the supply of make-to-order producers until they have real customer orders. The most used are the stochastic requirements planning methods, and the three most named in the literature are linear regression, moving average, and first-order exponential smoothing [42]. The following demand forecasting methods in Table 2 and in detail in Appendix A are applied to the conceptual model and compared based on the forecast accuracy to determine which method will be used for the next planning period:

Table 2. Demand forecasting methods (own elaboration based on $[42,43]$ ).

\begin{tabular}{ccc}
\hline No. & Demand Forecasting Method & Formula \\
\hline 1 & Cumulative moving average (CMA) & $F_{(\mathrm{t}+1)}=\frac{1}{n} \sum_{\mathrm{t}=1}^{\mathrm{n}}$ item demand $(\mathrm{t})$ \\
\hline 2 & Linear regression & $F_{(\mathrm{t}+1)}=a \times t_{\text {trend }}+b$. \\
\hline 3 & Exponential smoothing of the first order & $F_{(\mathrm{t}+1)}=\alpha \times D_{t}+(1-\alpha) \times F_{(t)}$ \\
\hline 4 & Exponential smoothing of the second order & $F_{(\mathrm{t}+1)}=\mathrm{L}_{(\mathrm{t})}+\mathrm{T}_{(\mathrm{t})}$ \\
\hline 5 & Exponential smoothing of the third order & $F_{(\mathrm{t}+1)}=\left(\mathrm{L}_{(\mathrm{t})}+\mathrm{T}_{(\mathrm{t})}\right) \times \mathrm{S}_{(\mathrm{t}+1-\mathrm{s})}$ \\
\hline 6 & Croston method & $F_{(\mathrm{t}+1)}=\frac{F_{(\mathrm{t})}}{\mathrm{E}_{(\mathrm{t})}}$ \\
\hline
\end{tabular}

The suitability of a forecasting method depends on the demand pattern [45]. Therefore, several models were selected in the model to select one matching demand and strategy. The comparison of the values calculated from the above-mentioned stochastic methods was performed with a randomly created future demand. This random data series as future demand was created based on a function in Vensim called Forecast. The forecasts of the different methods in the conceptual model were compared by means of the forecast error. There are different methods to measure and provide conclusions regarding the accuracy of the used forecast method [46]. The mean absolute deviation (MAD), the mean square error (MSE), and the mean absolute percentage error (MAPE) are methods in Appendix A that produce consistent results when comparing different forecasting methods [43]. As a result, the MAD method is considered in the conceptual model to assess the suitability of the previously mentioned demand forecasting techniques. The forecasting techniques are compared after every planning period within the simulation.

Using the forecasting method selected after the comparison, demand planning is performed according to different planning horizons that, as mentioned before, are related to the different decisions they influence. Therefore, demand is aggregated in weeks for short-term planning and in months and in quarters of a year to obtain demand forecasts based on the control loop for three different planning horizons. In summary, in the demand planning area, the model calculates the variation coefficient to provide an indication of the variability of the demand [43]. 


\subsection{Inventory Planning}

Inventory planning comprises the determination of the needed safety stock (SS) and stock for procurement order release [43]. For this, consistent inventory management and forecast values from the demand planning are needed [43]. The reason for safety stocks is motivated by the uncertainties coming from stock deviations, delivery dates, replenishment time (RT) deviations, quantity deviations, and demand volatility. The level of SS depends on the target service level (SL). In this context, Table A1 in Appendix A shows the value of the safety factor, $\mathrm{k}$, for the required service level. The calculation of the stock for procurement order release or reorder point(s) as well as for the calculation of safety stock are performed considering the replenishment times and demand deviations. Therefore, the model considers the stochastic demand and replenishment time and deterministic procurement quantity and stock level in each period. For the calculation of the safety stock in Table 3:

Table 3. Safety stock calculation (own elaboration).

\begin{tabular}{|c|c|c|}
\hline No. & Replenishment Method & Formula for Safety Stock \\
\hline & & $S S_{(t)}=f(R T, S L$, forecast failure $)$ \\
\hline 1 & Reorder point & $\begin{array}{l}=k \times \sqrt{\overline{R T} \times \sigma_{(D, t)}^{2}+F_{(t)}^{2} \times \sigma_{(R T, t)}^{2}} \\
+ \text { Backlogs }\end{array}$ \\
\hline 2 & EOQ & $S S_{(t)}=0$ \\
\hline
\end{tabular}

The safety factor, $\mathrm{k}$, is determined by the required service level. Initially, the model has a service level goal of $99 \%$, and, therefore, $\mathrm{k}$ is equal to 2.33 [43]. By using a dynamic calculation of safety stocks and of the reorder point notification considering the market and production deviations, it is possible to obtain systematic inventory planning depending on the required service level and reducing the probability of stockouts without unnecessarily increasing the inventory level [43]. In the simulation models, the safety stock depends on the replenishment method used. In the EOQ, the safety stocks (SS) are equal to zero. In the EOQ method, this is due to the nature of the method that always sends a certain quantity every fixed value of weeks, as this is a method to deal with non-variability demands and where forecast errors are small [42]. The stock for procurement order release are presented for the reorder point and for the EOQ method in Table 4:

Table 4. Stock for procurement order release (own elaboration).

\begin{tabular}{|c|c|c|}
\hline No. & Replenishment Method & Stock for Procurement Order Release \\
\hline 1 & Reorder point & 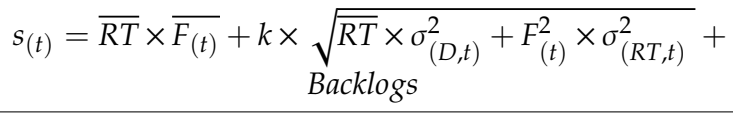 \\
\hline 2 & EOQ & $\begin{array}{l}\text { Stock level at } \mathrm{t} \text {, when weeks between last } \\
\text { order release } \\
\text { equals weeks between the last procurement order }\end{array}$ \\
\hline
\end{tabular}

\subsection{Procurement Planning}

Procurement planning takes care of the procurement initiation and the selection of the order quantity and lot size. In the different procurement policies, the two parameters, order quantity and order frequency, can be variable or constant [47] as shown in Table 5. If the four characteristics of the two parameters, order size and order frequency, are combined, there are four different procurement ordering strategies [48]. In the reorder-point-method, the inventory level is checked after each stock movement to control if the remaining inventory is below the reorder-point, $\mathrm{s}$. If this is the case, then an order is placed [41]. 
Table 5. Overview of the possible ordering policies (own elaboration based on [48]).

\begin{tabular}{|c|c|c|}
\hline $\begin{array}{l}\text { Order Cycle } \\
\text { Order Quantity }\end{array}$ & $\begin{array}{c}\text { Fix } \\
\text { (Order Rhythm Method) }\end{array}$ & $\begin{array}{c}\text { Variable } \\
\text { (Reorder Point Method) }\end{array}$ \\
\hline Fix & t, q-Policy & s, q-Policy \\
\hline Variable & t, S-Policy & s, S-Policy \\
\hline
\end{tabular}

$\mathrm{t}=$ Fixed period between two order (order rhythm); $\mathrm{q}=$ order quantity; $\mathrm{s}=$ stock that triggers an order (reorder point).

$\mathrm{S}=$ Target stockA third method called control-rhythm comes from another combination of the parameters. These are $(t, s, q)$ - and $(t, s, S)$-policies [43] in which the stock is periodically controlled, each $\mathrm{t}$ periods, and if the stock level is below the reorder-point, $\mathrm{s}$, then a new order is placed. A fourth procurement initiation method is a demand-related-method when the future demand is known based on real orders. In the conceptual model, it is assumed that real orders are not known, or the uncertainty about them is high; thereby, the model is based on the stochastic analysis.

In inventory planning, the inventory replenishment times and size are often revised depending on the real demand leading to changes for the rest of the planning horizon as a planning instability or so-called system nervousness [7]. The (s, S)-policy was shown to be cost-optimal in both stationary and non-stationary demand cases [7] although other authors, such as de Kok and Inderfurth [49] questioned the performance of this policy in the stationary demand case based on a third criterion, with regard to a defined service level, which is the level of planning stability [7].

The calculation of the procurement order quantity pursues the goal of defining a cost-optimized procurement quantity considering the demand forecast [42]. As a basis, we considered two main types of procurement order quantities, constant, $q$, and variable, depending on the target level, $\mathrm{S}$, as shown in Table 6:

- Constant order quantity (q): The most used, in practice, is the classical economic order quantity (EOQ) with the Andler-Harris formula for the optimal batch size. The optimal batch size is always calculated for a certain period, in this case, for a year [46]. The economic order quantity (EOQ) that has been considered also takes care of the back-ordered units, finding the optimal quantity to order between four components: the cost per unit, the procurement cost per order, the inventory holding cost, and the backlog penalty cost [50]. This order quantity strategy can be applied with a dynamic calculation each period or with a discrete calculation valid for a period, such as a year. In the first case, the EOQ is calculated every week depending on the current demand pattern of the customers, i.e., an EOQ that changes depending on the expected demand for the next year. In the second case, based on the demand forecast for the next year, the EOQ is fixed for the next year, and the value does not change until the next planning year. With the EOQ calculated, the number of expected orders for the next year is derived; however, this number is typically not an integer, and therefore an adjustment is necessary. The weeks between orders are truncated to an integer, and then the EOQ is adjusted by maintaining the total expected demand for the next year.

- Variable order quantity (depending on the target level, S): The inventory is filled up to a target level [47]. This is one of the options of the dynamic or feedback-dependent model. The model uses the reorder point with variable order quantity to respond dynamically. This method requires a high administration and IT effort to check the stocks after each transaction [43]. It is usually applicable for high-value goods with variable demand. The time frame between procurement orders varies. To define the target level (S), it should be a level defined by an invariant formula, but whose parameters vary over time. As a result, the target level varies over time, and so does the order quantity to reach it. This ordering method is able to change the target level to respond to customer demands, their volatility, and existing delivery backlogs. After this, the definition can determine the quantity ordered, $Q_{R P}$, in the model, when the stock drops under the reorder 
point (s). With this quantity ordered, a warehouse is planned to have sufficient products to meet customer demands for a period equal to two times the replenishment time.

Table 6. Procurement order quantity (own elaboration).

\begin{tabular}{|c|c|c|}
\hline No. & Replenishment Method & Procurement Order Quantity \\
\hline 1 & Reorder point & $\begin{array}{c}Q_{R P}=2 \times B S+S S+\text { Customer backlogs } \\
- \text { Virtual inventory }\end{array}$ \\
\hline 2 & EOQ (backordering) & $\begin{array}{r}q=Q_{E O Q \text { Backordering }}=Q_{E} \times Q_{B} \\
=\sqrt{\frac{2 \times A \times S}{I \times C}} \times \sqrt{\frac{I \times C+\pi}{\pi}}\end{array}$ \\
\hline
\end{tabular}

One of the simulation models is capable of shaping its strategy depending on customer demand. The model can do so by changing procurement policies. One of the criteria used for deciding these changes is the variation coefficient, which gives an indication of the variability of the demand. Due to this, the reorder point deals better with demand uncertainty. When the variation coefficient is higher, the demand uncertainty is also higher.

\subsection{Key Performance Indicators for an Inventory Management Model}

A major reason for organizations to undertake activities is to save money or increase profit, or influence other important factors, such as quality, delivery time, or delivery reliability, which are essential for competitiveness [1]. The results will be quantitative to evaluate the response according to the following key performance indicators (KPIs) divided into the defining parameters of a specific scenario and the system efficiency indicators, including the economic parameters as shown in Table 7. The detailed explanations and formulae of the KPIs are described in Appendix B. The values of the KPIs refer to the sum of all stages of the supply chain, such as the average work in process (WIP) stock except for specific KPIs, such as the average procurement quantity, average stock at Tier 1 producer or original equipment manufacturer (OEM), and the end-customer KPIs, such as the service level:

Table 7. KPIs for an inventory management model (own elaboration based on [42,43] and [51]).

\begin{tabular}{|c|c|c|}
\hline No. & Key Indicator & Formula \\
\hline 1 & $\sum$ Demand (products) & $\sum_{t=1}^{n}$ Demand at time period $t$ \\
\hline 2 & MAD of the forecast (products) & $\frac{\sum_{t=1}^{n}|D(t)-F(t)|}{\sum_{t=1}^{n} t}$ \\
\hline 3 & Ø WIP stock (products) & $\frac{\sum_{t=1}^{n} \text { Stock at the warehouses at time } t}{\sum_{t=1}^{n} t}$ \\
\hline 4 & $\begin{array}{c}\varnothing \text { stock at Tier } 1 \text { producer } \\
\text { (products) }\end{array}$ & $\frac{\sum_{t=1}^{n} \text { Stock at the Tier- } 1 \text { warehouses at time } t}{\sum_{t=1}^{n} t}$ \\
\hline 5 & $\begin{array}{l}\varnothing \text { stock at OEM producer } \\
\text { (products) }\end{array}$ & $\frac{\sum_{t=1}^{n} \text { Stock at the OEM producer warehouses at time } t}{\sum_{t=1}^{n} t}$ \\
\hline 6 & Utilization rate of employees (\%) & $\frac{\sum_{t=1}^{n} \text { Capacity used }}{\sum_{t=1}^{n}(\text { Capacity per employee } * \text { No. of employees })} \times 100 \%$ \\
\hline 7 & On-time delivery (\%) & $\frac{\sum_{t=1}^{n} \text { Products delivered on time }}{\sum_{t=1}^{n} \text { Total products ordered }} \times 100 \%$ \\
\hline 8 & Service level (\%) & $\frac{\sum_{t=1}^{n} \text { Weeks without product backlog }}{\sum_{t=1}^{n} t} \times 100 \%$ \\
\hline 9 & $\begin{array}{l}\varnothing \text { Procurement quantity } \\
\text { (products) }\end{array}$ & $\frac{\sum_{t=1}^{n} \text { Procurement } \text { Quantity }}{\sum_{t=1}^{n} \text { Procurement orders placed until time } t} \times 100 \%$ \\
\hline 10 & $\varnothing$ Customer backlog (products) & $\frac{\sum_{t=1}^{n} \text { Customer backlog (products) }}{\sum_{t=1}^{n} t}$. \\
\hline 11 & $\begin{array}{c}\sum \text { Weeks with customer backlog } \\
\text { (weeks) }\end{array}$ & $\sum_{t=1}^{\mathrm{n}}$ Customer backlog (weeks). \\
\hline
\end{tabular}


Table 7. Cont.

\begin{tabular}{ccc}
\hline No. & Key Indicator & Formula \\
\hline 12 & $\sum$ Inventory costs (mil. USD) & Warehouse Storage costs + Stockout costs. \\
\hline 13 & $\sum$ Procurement costs (mil. USD) & $\sum_{t=1}^{n}$ Units $\times$ Cost per Unit + Orders $\times$ \\
& Cost per Order \\
\hline 14 & $\sum$ Capital commitment costs (mil. & $\sum_{t=1}^{n}$ Inventory value $\times$ Storage time $\times$ Interest rate \\
\hline 15 & $\sum$ Storage costs (mil. USD) & $\sum_{t=1}^{n}$ Personnel costs \\
\hline 16 & $\sum$ Stockout costs (mil. USD) & $\sum_{t=1}^{n}$ Penalty per unit backlogged $\times$ units backlogged \\
\hline 17 & $\sum$ Investment costs (mil. USD) & $\sum_{t=1}^{n}$ Investment per time period \\
\hline
\end{tabular}

\subsection{Design of Case Study to Test the Model Depending on the Product Lifecycle}

First, the modeler must define a time horizon and units of time. It is easy to conduct this step by asking to what extent the simulation should be considered. In the case of this study, we decided to simulate eight working years to evaluate the influences in the short, medium, and long term. The simulation was performed with 400 time periods, each representing one producing week, counting a total of eight years of production, which represents the lifecycle of the product in consideration. The lifetime of car models in the past decade in the more advanced countries decreased on average from eight to almost four years [52].

Second, the supply chain structure is set to apply the conceptual model and to be able to simulate it under certain conditions. The structure consists of a Tier 1 supplier and an OEM Producer as shown in Figure 3. The hierarchical supplier network is divided into three tiers, with the Tier 1 suppliers as producers of completed modules (e.g., dashboard, engine, seats, etc.) with their own manufacturing capabilities or montage [53]. Both have their warehouses of raw materials and finished products in addition to their production facilities. Finally, end-customers are at the end of the chain receiving the products:

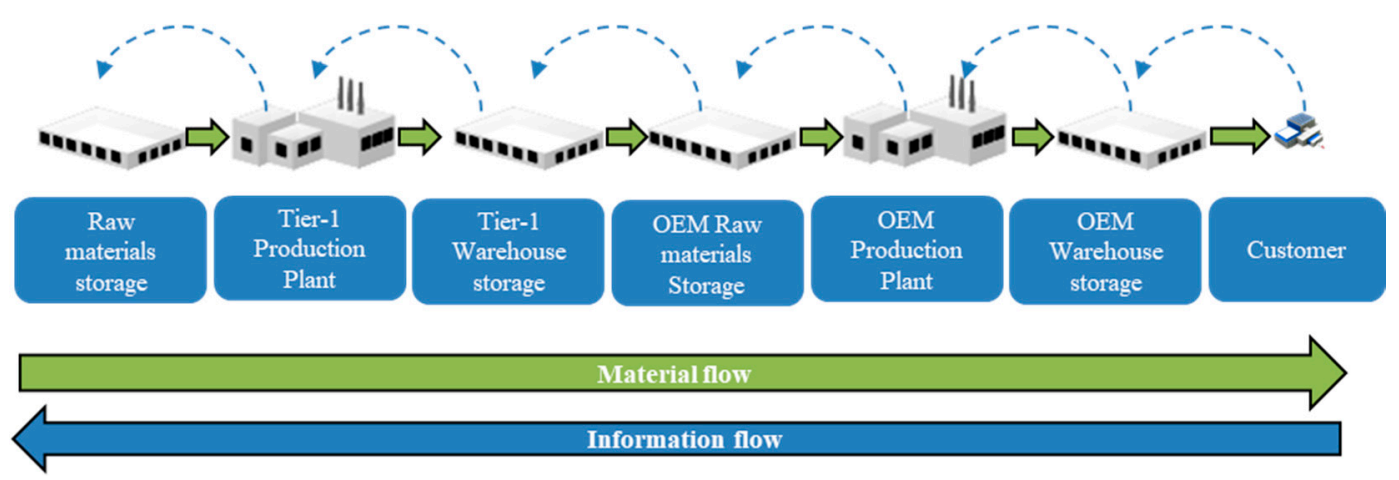

Figure 3. Supply chain structure of the case study (own elaboration). Original equipment manufacturer (OEM).

Third, general assumptions were made to be able to answer the research question allowing the reduction of model complexity. The following assumptions were applied to all scenarios and models of the case study:

- The product is a finished/sale product after the OEM production facility; 
- The orders have only one product type; There is only this product type in the supply chain model considered;

- There is no transport limitation, or transport means limitation between the different stages;

- The replenishment times between stages at the beginning of the case study have the same distribution over the period considered;

- A steady supply of materials for the production process of the Tier 1 supplier is given;

- The stock and products in the transport process are known in every moment, assuming a calculation after each transaction along the supply chain;

- Order information along the supply chain is available;

- Demand is not known, but historical data for all customers is available one week after the demand;

- Customers do not leave the company or order before or more if the last orders were not met on time;

- In the beginning, all employees have the same experience and have the same capacity to perform warehouse activities. Employees characteristics, such as age or experience, are variables that can be parameterized in the model to assess their influence;

- The production capacity is always between a minimum and a maximum, given a capacity per shift and the number of employees if no decision has been taken along the simulation. The minimum and maximum production capacities per shift are the same for all models at the beginning of the simulation study;

- The storage capacities have a maximum level, and it is the same for all models at the beginning of the simulation;

- Maintenance is not considered in the production facilities nor in the storage warehouses;

- Products do not suffer any kind of problems/failure in their transportation from the production facility to the customers;

- Packaging is already performed in the production facility.

As a fourth step, the exogenous variables as inputs to the model are described. In the case study, these are:

- Market demand: This is defined by values read from a database outside of the model. Demand defines the evolution of customer requests and the phase of the product lifecycle. The length of the product lifecycle is also an input that can influence the decision-making process depending on the risk.

- Supply chain flow: There are two configurations: the supply chain can contain WIP products or not. The first represents a supply chain flow already in existence, and the second represents a new supply chain flow of products. The scenarios simulated are from the first type.

- Production capacity: There is a maximum of 900 units per week in three shifts at the beginning of the simulation. During the simulation, investment options are considered for increasing the capacity if needed and if the conditions for the decision are given.

- The storage capacity at the beginning of the simulation is five weeks for Tier 1 and for the OEM manufacturer for the maximum of 600 units per week considering two working shifts, therefore, totaling 3000 units of storage capacity.

- Working shifts: At the beginning of the simulation, there are two working shifts.

- The personnel capacity at the beginning of the simulation is a group of 20 employees at both warehouses of Tier 1 and OEM with a capacity of 15 units per shift to be processed.

- Investment, costs, prices, and interest rates: All these values per unit for the different types of economic parameters are inputs from outside of the model as well as the values of the investments for new capacities.

- Replenishment times between stages: The distribution is set at the beginning and can only change if a new warehouse is put in operation. 
Finally, the potential decisions, according to Section 3.1, are described:

- New Investment-new warehouse and production facilities: This can increase capacities as well as reduce lead times at both Tier 1 and OEM producers.

- Investment in the increase in production and storage capacities in the existing locations: This can increase capacities for both Tier 1 and OEM producers maintaining lead times.

- Demand planning: The decision of changing or not changing between the different forecasting methods applied to the conceptual model based on the forecast error. The change has impacts on all levels of the planning and organizational decisions.

- Planning decisions:

- Inventory planning: safety stock level $(\mathrm{k})$ changes as required for the target service level. This also decides whether to order each t periods or when the inventory drops under $\mathrm{s}$, the reorder point level.

- Procurement planning: The selection of one of the four policies of Table 5 as it is assumed that the inventory is checked after each stock movement. The $(t, q)$ applies an economic order quantity calculated once and applied until the policy changed, the $(\mathrm{t}, \mathrm{S})$ strategy has a constant distance between orders and the $S$ is calculated based on a dynamic target level consisting of safety stock and base stock. The (s, q)-Policy applies an economic order quantity calculated each time the inventory level drops below the reorder point, and the (s, S)-Policy orders the quantity to reach the target level, S, when inventory drops below s.

- Organizational decisions:

- Number of working shifts: Based on the demand forecast, the planning of 3, 2, or 1 working shift is performed.

- Production output: Monthly planning of the target production output is performed by leveling the production quantities based on a given demand forecast for a planning horizon of a month, 4 weeks in the simulation.

- Number of employees: The number of employees per shift. At the operational level, the forecast influences the number of employees working every week to adapt the system to customer demand.

\subsection{Simulation Models}

Based on the basic framework and on the following characteristics, different types of simulation models can be derived:

1. Forecasting method:

a. The forecasting method is the same over the lifecycle. It allows changes in the parameters of the method over time.

b. The forecasting method changes over time depending on selected criteria, such as the forecast error within a certain period. This also allows changes in the parameters of the method over time.

2. Procurement policy:

a. The procurement policy is the same over the lifecycle. This allows changes in the parameters of the method over time.

b. The procurement policy changes over time depending on selected criteria, such as the variation coefficient within a certain period. This also allows changes in the parameters of the method over time. 
3. Strategy for decision-making and product lifecycle:

a. Decisions at all levels, strategic, tactical, and operational, including investments, employee characteristics, and as well as the safety factor, $\mathrm{k}$, do not depend on the product lifecycle.

b. Decisions at all levels, strategic, tactical, and operational, depending on the product lifecycle. Criteria such as years or time until end-of-lifecycle are considered.

As a result of the above-mentioned possibilities and their methods, multiple combinations of models can be obtained. However, to check the hypothesis of a model able to respond to market demands by applying a feedback control loop, the research proposes the following models as shown in Figure 4:

- EOQ simulation model: This is described by a model applying 1a with a cumulative moving average as a forecasting method, 2a with a $(t, q)$-policy with an EOQ order quantity and 3a with decisions not dependent on the product lifecycle.

- Reorder point simulation model: This is a model described by 1a with a cumulative moving average as a forecasting method, $2 \mathrm{a}$ with an (s, S)-policy, reorder point policy and 3a with decisions not dependent on the product lifecycle.

- Market-oriented simulation model with 1b, i.e., one of the methods described in Section 3.2 with the possibility to change to another method based on selected criteria, such as the forecast error. Moreover, this model is described by $2 b$ selecting one of the four policies in Table 5 and has the capability of changing to other policies and by $3 \mathrm{~b}$ with decisions dependent on the product lifecycle.

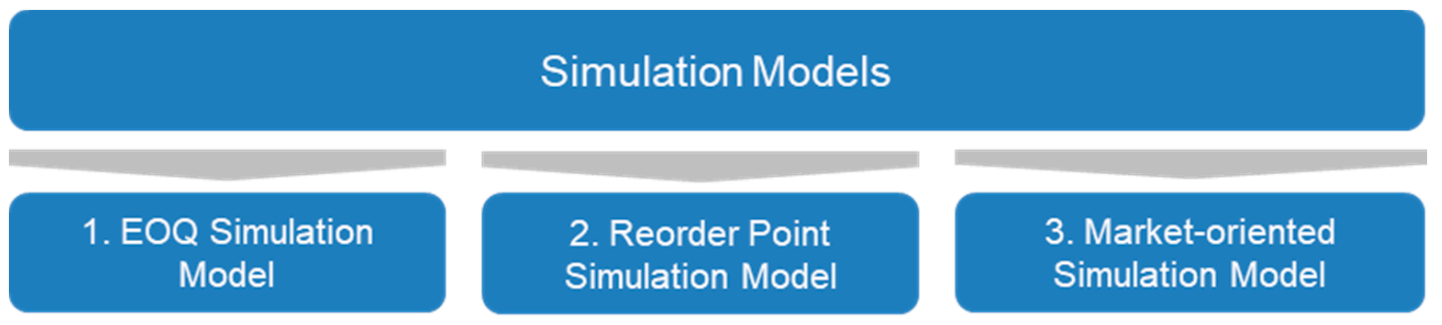

Figure 4. Simulation models (own elaboration). Economic order quantity (EOQ).

The EOQ and Reorder-Point models are models based on the literature, while the third model, the market-oriented model, was built based on the cybernetic model developed within the research. The characteristics of the models are described in Table 8: 
Table 8. Differences between the simulation models (own elaboration).

\begin{tabular}{|c|c|c|c|c|}
\hline No. & Area & 1. EOQ Simulation Model & $\begin{array}{l}\text { 2. Reorder-Point } \\
\text { Simulation Model }\end{array}$ & $\begin{array}{l}\text { 3. Market-Oriented } \\
\text { Simulation Model }\end{array}$ \\
\hline 1 & Demand planning & Cumulative moving average & $\begin{array}{l}\text { Cumulative moving } \\
\text { average }\end{array}$ & $\begin{array}{l}\text { Decision between: } \\
\text { - } \quad \text { Moving average } \\
\text { - } \quad \text { Linear regression } \\
\text { smoothing of 1st, 2nd, } \\
\text { or 3rd order } \\
\text { - Croston method } \\
\text { Use of random numbers } \\
\text { for comparing forecast } \\
\text { versus a generated } \\
\text { random demand }\end{array}$ \\
\hline 2 & Inventory planning & $\begin{array}{l}\text { No safety stock } \\
\text { Reorder point each number } \\
\text { of weeks based on the EOQ }\end{array}$ & $\begin{array}{l}\text { Safety stock for the service } \\
\text { level of } 99 \% \\
\text { reorder point = base stock } \\
+ \text { safety stock }\end{array}$ & $\begin{array}{l}\text { Decision between: } \\
\text { - } \quad \text { Dynamic EOQ }(\mathrm{t}, \mathrm{q}) \\
\text { - } \quad \text { Reorder point }(\mathrm{s}, \mathrm{S})\end{array}$ \\
\hline 3 & $\begin{array}{l}\text { Procurement } \\
\text { planning }\end{array}$ & $\begin{array}{l}\text { Order release each number } \\
\text { of weeks based on the EOQ } \\
\text { dynamic EOQ based on } \\
\text { the forecast }\end{array}$ & $\begin{array}{l}\text { Order release when } \\
\text { inventory drops under } \\
\text { the reorder-point } \\
2 \times \mathrm{BS}+\mathrm{SS}+\text { customer } \\
\text { backlogs - virtual } \\
\text { inventory }\end{array}$ & $\begin{array}{l}\text { Decision between: } \\
\text { - } \quad \text { Dynamic EOQ }(\mathrm{t}, \mathrm{q}) \\
\text { - } \quad \text { Reorder point }(\mathrm{s}, \mathrm{S})\end{array}$ \\
\hline 4 & $\begin{array}{l}\text { Organizational } \\
\text { decisions }\end{array}$ & $\begin{array}{l}\text { Decision on: } \\
\text { - } \quad \text { Number of employees } \\
\text { - } \quad \text { Production output } \\
\text { - Number of shifts }\end{array}$ & $\begin{array}{l}\text { Decision on: } \\
\begin{array}{l}\text { - } \\
\text { Number of } \\
\text { - } \quad \text { Production output } \\
\text { - } \quad \text { Number of shifts }\end{array}\end{array}$ & $\begin{array}{l}\text { Decision on: } \\
\text { - } \quad \text { Number of } \\
\text { - } \quad \text { Productoyees per shift } \\
\text { - } \quad \text { Number of shifts }\end{array}$ \\
\hline 5 & $\begin{array}{l}\text { Investment-risk } \\
\text { strategy }\end{array}$ & $\begin{array}{l}\text { Decision on increasing: } \\
\text { - } \quad \text { Storage capacity } \\
\text { - } \quad \text { Production capacity }\end{array}$ & $\begin{array}{l}\text { Decision on increasing: } \\
\text { - } \quad \text { Storage capacity } \\
\text { - } \quad \text { Production capacity }\end{array}$ & $\begin{array}{l}\text { Decision on increasing: } \\
\text { - } \quad \text { Storage capacity } \\
\text { - } \quad \text { Production capacity }\end{array}$ \\
\hline
\end{tabular}

The organizational decisions are based on forecasts for the related planning horizons. The investment options are analyzed attending to static limits for the EOQ and RP model, while, for the market-oriented model, the investment options are assessed with control limits depending on the product lifecycle and demand planning.

Decisions and changes in the simulation model are performed autonomously. The observer can analyze the results and changes for the selected simulation model to answer and to derive strategies for the potential what-if-scenarios.

\subsection{Simulation Models Validation}

Before the results from the model were extracted and interpreted, a formal validation was performed. According to Sterman [54], there are 12 possible methods for validating system dynamics models [55]. There are three that are relevant to our models; one of them is the extreme-value test, which we used in this paper. An application of this method proved that the model's response was plausible when taking extreme values for different input parameters. Certain basic physical laws should be examined: for example, when there are no employees, the model's output should not be able to meet the demand. For the three models, the same input and output variables were chosen to analyze and validate the models. These input variables were the production capacity per shift and 
customer demand. From the variation in these variables, the following can be expected for the results to be logical and the model to be validated:

- For a lower nominal capacity per shift (units per week), the customer backlog, total production, and working shifts must be higher, and the products in the OEM warehouse storage must be lower.

- For a higher customer demand (units per week), the customer backlog, total production, and working shifts must be higher, and the products in the OEM warehouse storage must be lower, as shown in Figure 5. The red lines indicate the lower nominal capacity, and the blue lines indicate the higher nominal capacity per shift.
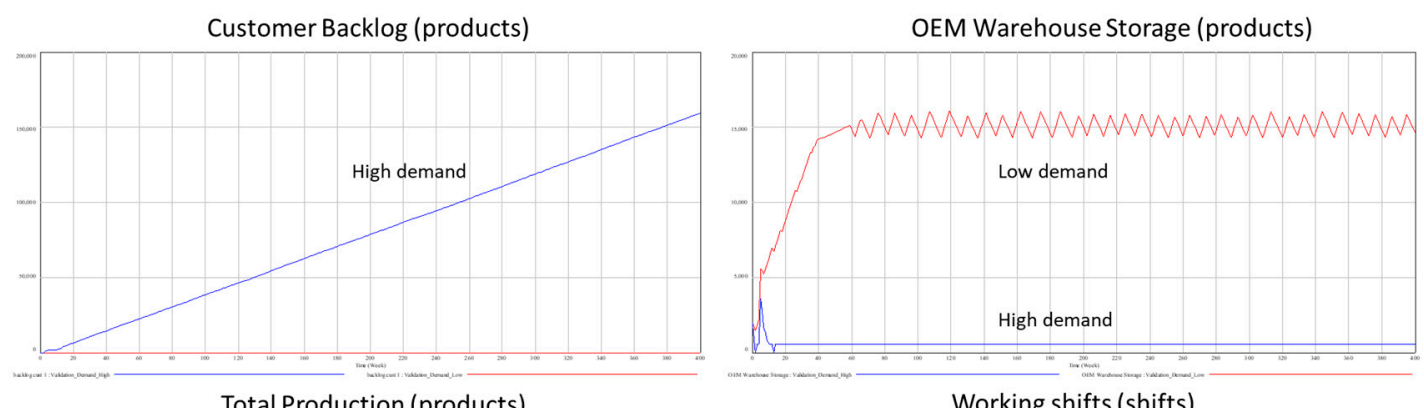

Total Production (products)
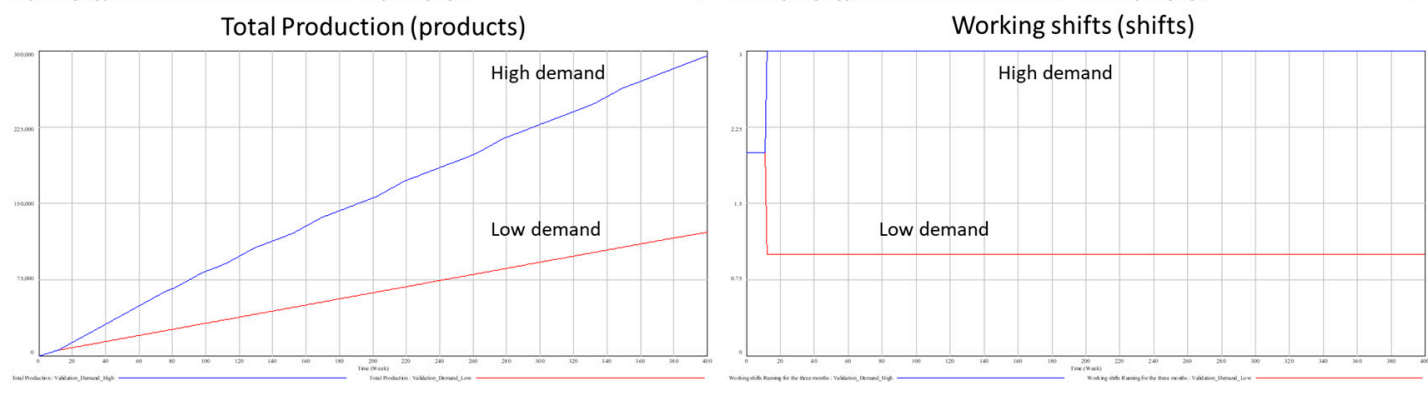

Figure 5. Generated demand scenarios based on lifecycle demand patterns (own elaboration).

\section{Results and Discussion}

\subsection{Scenarios}

Scenarios for the simulation case study were based on different patterns and values of customer demand over the product lifecycle in the 400 periods, weeks, counting for eight years of the product lifecycle as shown in Figure 6. The demand patterns of the five scenarios were based on the six demand patterns types described by Cox [56] and on the twelve types described by Rink and Swan [57]:

1. First demand scenario: This represents the classical, the growth-decline-plateau, and the rapid penetration lifecycle demand patterns of Rink and Swan [57];

2. Second demand scenario: This represents the cycle-recycle and the cycle-half recycle lifecycle demand patterns of Rink and Swan [57];

3. Third demand scenario: This represents the stable maturity and the high and low plateau lifecycle demand pattern of Rink and Swan [57];

4. Fourth demand scenario: This represents the growing maturity and the innovative maturity lifecycle demand patterns of Rink and Swan [57];

5. Fifth demand scenario: This represents the increasing and decreasing sales lifecycle demand patterns of Rink and Swan [57]. 

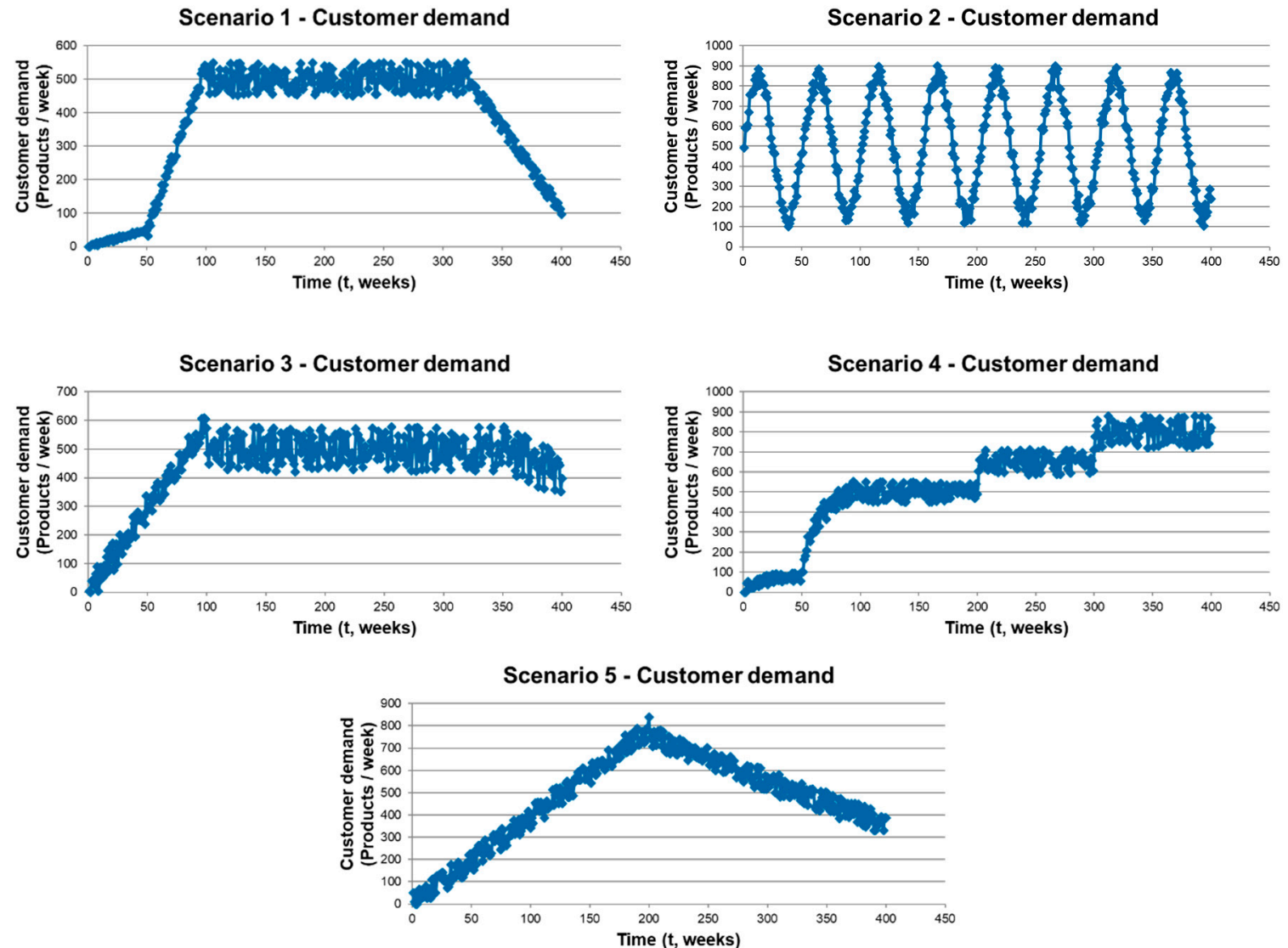

Figure 6. Generated demand scenarios based on lifecycle demand patterns (own elaboration).

\subsection{Simulation Results}

The simulation results for the three models within two out of the five scenarios are presented in the following tables:

As can be seen in Table 9, the demand was assumed the same in all three models. The MAD was more than two times lower for the market-oriented (MO) model due to the selection of the forecasting technique based on the set of methods presented in Section 3. Based on this selection, the MO model can minimize the uncertainty of procurement planning. In addition, inventories were lower for the EOQ model due to its lack of safety stocks in the model.

In this scenario, there was only a small effect on the OTD and Service Level due to the fact that the average demand of this scenario was low and because the stationary demand trend was the most common over the lifecycle. As a result, for the service level and OTD performance of the models, all three models presented values of $100 \%$, with a small decrease for the EOQ model due to a week with backlogged delivery. An area of difference in the models was the average procurement quantity, as, while the EOQ and the MO models presented values near 2000 units, the Reorder-Point (RP) model had almost 4000 products as average.

Regarding the cost analysis, the MO model had the best performance with $10 \%$ less than the RP Model and 6\% less than the EOQ Model. The MO model opened a new warehouse in week 21, while the other two models opened a new warehouse around week 120 . To summarize, for this scenario and lifecycle-demand curve, the MO model presented the best performance for the service level as it equaled the others or was better and had lower inventory costs with higher capacity utilization of employees as it adapted all areas of inventory management to customer demand. 
Table 9. Simulation results for the first demand scenario.

\begin{tabular}{ccccc}
\hline No. & Key Indicator & $\begin{array}{c}\text { 1. EOQ } \\
\text { Simulation } \\
\text { Model }\end{array}$ & $\begin{array}{c}\text { 2. Reorder-Point } \\
\text { Simulation } \\
\text { Model }\end{array}$ & $\begin{array}{c}\text { 3. Market-Oriented } \\
\text { Simulation Model }\end{array}$ \\
\hline 1 & E Demand (products) & 149,965 & 149,965 & 149,965 \\
2 & MAD of the forecast (products) & 42.0 & 42.0 & 18.3 \\
3 & $\varnothing$ WIP stock (products) & 16,262 & 19,640 & 17,769 \\
4 & $\varnothing$ stock at Tier 1 producer (products) & 11,817 & 10,467 & 12,743 \\
5 & $\varnothing$ stock at OEM producer (products) & 4446 & 9173 & 5026 \\
6 & Utilization rate of employees (\%) & 70.1 & 72.9 & 98.9 \\
7 & On-time delivery (\%) & 99.9 & 100.0 & 100.0 \\
8 & Service level (\%) & 99.8 & 100.0 & 100.0 \\
9 & $\varnothing$ Procurement quantity (products) & 2077 & 3741 & 0 \\
10 & $\varnothing$ Customer backlog (products) & 0.1 & 0 & 0 \\
11 & $\sum$ Weeks with customer backlog (weeks) & 1 & 0 & 3370 \\
12 & $\sum$ Inventory costs (mil. USD) & 3567 & 3737 & 1538 \\
13 & $\sum$ Procurement costs (mil. USD) & 1628 & 1538 & 1752 \\
14 & $\sum$ Capital commitment costs (mil. USD) & 1823 & 2083 & 80 \\
15 & $\sum$ Storage costs (mil. USD) & 116 & 116 & 0 \\
16 & $\sum$ Stock-out costs (mil. USD) & 0.4 & 0 & $338(\mathrm{t}=21)$ \\
17 & $\sum$ Investment costs (mil. USD) & $310(\mathrm{t}=124)$ & $326(\mathrm{t}=114)$ & \\
\hline
\end{tabular}

As can be seen in Table 10, the demand was assumed the same in all three models. The MAD was almost eight times lower for the market-oriented (MO) model due to the selection of the best-fit and accurate forecasting technique and also due to the fact that the other two models performed demand forecasting with the cumulative moving average method, and this was not suitable as the forecast error was high. In addition, inventories were lower for the EOQ model due to its lack of safety stocks in the model leading to low OTD at $62 \%$, and Service Level at $61 \%$, since the seasonal demand pattern trend was dominant in this scenario.

Table 10. Simulation results for the second demand scenario.

\begin{tabular}{ccccc}
\hline No. & Key Indicator & $\begin{array}{c}\text { 1. EOQ } \\
\text { Simulation Model }\end{array}$ & $\begin{array}{c}\text { 2. Reorder-Point } \\
\text { Simulation Model }\end{array}$ & $\begin{array}{c}\text { 3. Market-Oriented } \\
\text { Simulation Model }\end{array}$ \\
\hline 1 & $\sum$ Demand (products) & 201,273 & 201,273 & 201,273 \\
2 & MAD of the forecast (products) & 163.6 & 163.6 & 23.7 \\
3 & $\varnothing$ WIP stock (products) & 6773 & 11,986 & 12,712 \\
4 & $\varnothing$ stock at Tier 1 producer (products) & 4745 & 4593 & 5039 \\
5 & $\varnothing$ stock at OEM producer (products) & 2028 & 7393 & 7612 \\
6 & Utilization rate of employees (\%) & 74.5 & 79.3 & 99.2 \\
7 & On-time delivery (\%) & 62.2 & 96.9 & 98.7 \\
8 & Service level (\%) & 60.8 & 93.3 & 98.8 \\
9 & $\varnothing$ Procurement quantity (products) & 2120 & 4262 & 3798 \\
10 & $\varnothing$ Customer backlog (products) & 177.0 & 15.8 & 5 \\
11 & $\sum$ Weeks with customer backlog (weeks) & 157 & 27 & 3514 \\
12 & $\sum$ Inventory costs (mil. USD) & 4135 & 3606 & 2018 \\
13 & $\sum$ Procurement costs (mil. USD) & 1938 & 2051 & 1293 \\
14 & $\sum$ Capital commitment costs (mil. USD) & 643 & 1291 & 107 \\
15 & $\sum$ Storage costs (mil. USD) & 138 & 138 & 54 \\
16 & $\sum$ Stock-out costs (mil. USD) & 1416 & 126 & $381(\mathrm{t}=72)$ \\
17 & $\sum$ Investment costs (mil. USD) & $123(\mathrm{t}=109)$ & $166(\mathrm{t}=327)$ & \\
\hline
\end{tabular}

On the other hand, the RP and the MO models presented service level and OTD values higher than $90 \%$. The difference between both is that the MO model had slightly better performance in service level, $5 \%$ more, in OTD, $2 \%$ more, and with 5 weeks of delays, while the RP model had 27 weeks of delays. In scenario 1 , the average procurement quantity of the MO model was closer to the quantity of the EOQ model; in this case, the procurement quantity was like the RP model. The utilization rate of the employee capacity was lower than $80 \%$ for the EOQ and RP models, while the MO model had a $99 \%$ utilization leading to almost $20 \%$ fewer storage costs. 
Regarding the cost analysis, the MO model had the best performance with almost USD 100 mil. less costs compared with the RP model and more than USD 600 mil. less than the EOQ model. In addition, the MO model opened a new warehouse in week 72, enabling high service level assurance with more storage capacity and shorter lead times, while the other two models opened a new warehouse later. To summarize, for this scenario and lifecycle-demand curve, the MO model presented the best performance for the service level and had the lower inventory costs with the higher capacity utilization of employees as it adapted all areas of inventory management to the customer demand.

As can be seen in Table 11, the MAD was more than three times lower for the market-oriented (MO) model due to the selection of the forecasting technique based on the set of methods presented in Section 3. In addition, inventories were lower for the EOQ model due to its lack of safety stocks in the model, while the other two models presented inventories of around 14,000 units on average. The service level and OTD were 100\% for the RP and the MO models, while the EOQ model had a $96 \%$ OTD and $89 \%$ service level due to 46 weeks with 18 units backlogged on average. An area of difference in the models was the average procurement quantity, with the EOQ model closer to 2000 units, the RP model with almost 5000 units, and the MO model was in the middle with 3200 units. This can be explained by the fact that the MO model used and changed from the EOQ to the RP methods depending on the system conditions. Regarding the cost analysis, the MO model had better performance with almost USD 250 mil. less than the RP model and a slightly worse result than the EOQ model, with USD 36 mil. lower costs.

The MO model opened a new warehouse in week 21, while the EOQ model did not open a warehouse, and the RP model opened one later in week 297. To summarize, for this scenario and lifecycle-demand curve, the MO model presented the best performance for service level as it equaled the RP model and had a slightly worse result in inventory costs compared with the EOQ model while securing higher service level and higher capacity utilization of employees as it adapted all areas of inventory management to the customer demand.

Table 11. Simulation results for the third demand scenario.

\begin{tabular}{ccccc}
\hline No. & Key Indicator & $\begin{array}{c}\text { 1. EOQ } \\
\text { Simulation Model }\end{array}$ & $\begin{array}{c}\text { 2. Reorder-Point } \\
\text { Simulation Model }\end{array}$ & $\begin{array}{c}\text { 3. Market-Oriented } \\
\text { Simulation Model }\end{array}$ \\
\hline 1 & D Demand (products) & 176,481 & 176,481 & 176,481 \\
2 & MAD of the forecast (products) & 55.2 & 55.2 & 16.7 \\
3 & $\varnothing$ WIP stock (products) & 9200 & 13,859 & 14,046 \\
4 & $\varnothing$ stock at Tier 1 producer (products) & 6109 & 5261 & 3954 \\
5 & $\varnothing$ stock at OEM producer (products) & 3091 & 8598 & 10,093 \\
6 & Utilization rate of employees (\%) & 77.2 & 80.0 & 99.1 \\
7 & On-time delivery (\%) & 96.0 & 100.0 & 100.0 \\
8 & Service level (\%) & 88.5 & 100.0 & 100.0 \\
9 & $\varnothing$ Procurement quantity (products) & 2077 & 4745 & 3214 \\
10 & $\varnothing$ Customer backlog (products) & 17.7 & 0 & 0 \\
11 & $\sum$ Weeks with customer backlog (weeks) & 46 & 0 & 3157 \\
12 & $\sum$ Inventory costs (mil. USD) & 3121 & 3396 & 1773 \\
13 & $\sum$ Procurement costs (mil. USD) & 1816 & 1759 & 1293 \\
14 & $\sum$ Capital commitment costs (mil. USD) & 1043 & 1516 & 91 \\
15 & $\sum$ Storage costs (mil. USD) & 120 & 120 & 0 \\
16 & $\sum$ Stock-out costs (mil. USD) & 141 & 0 & $250(\mathrm{t}=21)$ \\
17 & $\sum$ Investment costs (mil. USD) & 0 & $194(\mathrm{t}=297)$ & \\
\hline
\end{tabular}

As can be seen in Table 12, inventories were lower for the EOQ model compared with the other models, with the MO model presenting $8 \%$ lower stocks than the RP model. In addition, the service level and OTD were $100 \%$ for the RP and the MO models, while the EOQ model had an $87 \%$ OTD and $83 \%$ service level due to 70 weeks with 61 units backlogged on average. The EOQ model had an average procurement quantity of 2400 units, while the RP model had around 2900 units, and the MO model with 2700 units. This can be explained by the fact that the MO model used and changed from the EOQ to the RP methods depending on the system conditions. Regarding the cost analysis, the MO 
model had better performance with $13 \%$ fewer costs compared with the EOQ model and with $9 \%$ less than the RP model. The MO model opened a new warehouse in week 60, while the EOQ model and the RP model opened a new warehouse later, around week 150. By using the MO model, the situation can be anticipated and the decision on a new investment based on the customer lifecycle of the product can take place. To summarize, for this scenario and lifecycle-demand curve, the MO model presented the best performance for the service level and inventory costs compared with both other models.

Table 12. Simulation results for the fourth demand scenario.

\begin{tabular}{ccccc}
\hline No. & Key Indicator & $\begin{array}{c}\text { 1. EOQ } \\
\text { Simulation Model }\end{array}$ & $\begin{array}{c}\text { 2. Reorder-Point } \\
\text { Simulation Model }\end{array}$ & $\begin{array}{c}\text { 3. Market-Oriented } \\
\text { Simulation Model }\end{array}$ \\
\hline 1 & $\sum$ Demand (products) & 217,581 & 217,581 & 217,581 \\
2 & MAD of the forecast (products) & 48.8 & 48.8 & 18.0 \\
3 & $\varnothing$ WIP stock (products) & 12,110 & 15,901 & 14,610 \\
4 & $\varnothing$ stock at Tier 1 producer (products) & 8460 & 6858 & 4309 \\
5 & $\varnothing$ stock at OEM producer (products) & 3651 & 9043 & 10,301 \\
6 & Utilization rate of employees (\%) & 75.1 & 79.0 & 99.2 \\
7 & On-time delivery (\%) & 86.7 & 100.0 & 100.0 \\
8 & Service level (\%) & 82.5 & 100.0 & 100.0 \\
9 & $\varnothing$ Procurement quantity (products) & 2400 & 2897 & 2702 \\
10 & $\varnothing$ Customer backlog (products) & 60.9 & 0 & 0 \\
11 & $\sum$ Weeks with customer backlog (weeks) & 70 & 0 & 0 \\
12 & $\sum$ Inventory costs (mil. USD) & 4242 & 4035 & 3689 \\
13 & $\sum$ Procurement costs (mil. USD) & 2217 & 2209 & 2197 \\
14 & $\sum$ Capital commitment costs (mil. USD) & 1387 & 1676 & 1379 \\
15 & $\sum$ Storage costs (mil. USD) & 150 & 150 & 0 \\
16 & $\sum$ Stock-out costs (mil. USD) & 487 & 0 & $343(\mathrm{t}=60)$ \\
17 & $\sum$ Investment costs (mil. USD) & $263(\mathrm{t}=158)$ & $276(\mathrm{t}=146)$ & \\
\hline
\end{tabular}

As can be seen in Table 13, the MAD was almost three times lower for the market-oriented (MO) model due to the selection of the forecasting technique based on the set of methods presented in Section 3. In addition, inventories were lower for the EOQ model than for the other models, with the MO model presenting almost $10 \%$ lower stocks than the EOQ model and almost $20 \%$ compared with the RP model. The service level and OTD were 100\% for the RP and the MO models, while the EOQ model had an $84 \%$ OTD and $78 \%$ service level due to 88 weeks with 75 units backlogged on average.

Table 13. Simulation results for the fifth demand scenario.

\begin{tabular}{ccccc}
\hline No. & Key Indicator & $\begin{array}{c}\text { 1. EOQ } \\
\text { Simulation Model }\end{array}$ & $\begin{array}{c}\text { 2. Reorder-Point } \\
\text { Simulation Model }\end{array}$ & $\begin{array}{c}\text { 3. Market-Oriented } \\
\text { Simulation Model }\end{array}$ \\
\hline 1 & D Demand (products) & 189,173 & 189,173 & 189,173 \\
2 & MAD of the forecast (products) & 45.2 & 45.2 & 17.6 \\
3 & $\varnothing$ WIP stock (products) & 14,704 & 16,766 & 13,338 \\
4 & $\varnothing$ stock at Tier 1 producer (products) & 11,304 & 6939 & 4542 \\
5 & $\varnothing$ stock at OEM producer (products) & 3400 & 9827 & 8796 \\
6 & Utilization rate of employees (\%) & 70.1 & 73.2 & 99.1 \\
7 & On-time delivery (\%) & 84.2 & 100.0 & 100.0 \\
8 & Service level (\%) & 78.0 & 100.0 & 100.0 \\
9 & $\varnothing$ Procurement quantity (products) & 2253 & 3432 & 2432 \\
10 & $\varnothing$ Customer backlog (products) & 74.9 & 0 & 0 \\
11 & $\sum$ Weeks with customer backlog (weeks) & 88 & 0 & 3277 \\
12 & $\sum$ Inventory costs (mil. USD) & 4356 & 3832 & 1929 \\
13 & $\sum$ Procurement costs (mil. USD) & 1946 & 1927 & 1246 \\
14 & $\sum$ Capital commitment costs (mil. USD) & 1670 & 1763 & 101 \\
15 & $\sum$ Storage costs (mil. USD) & 141 & 141 & 0 \\
16 & $\sum$ Stock-out costs (mil. USD) & 600 & 0 & $324(\mathrm{t}=63)$ \\
17 & $\sum$ Investment costs (mil. USD) & $273(\mathrm{t}=150)$ & $280(\mathrm{t}=141)$ & \\
\hline
\end{tabular}


The EOQ model had an average procurement quantity of around 2250 units, while the RP model had around 3400 units, and the MO model was in the middle but closer to the value of the EOQ model. This can be explained by the fact that the MO model used and changed from the EOQ to the RP methods depending on the system conditions. Regarding the cost analysis, the MO model had better performance with more than $25 \%$ fewer costs compared with the EOQ model and with almost $15 \%$ less than the RP model.

The MO model opened a new warehouse in week 63, while the EOQ model and the RP model opened a new warehouse later, around week 150. By doing so, these models did not adapt their storage capacities for the required stock, while the MO model anticipated the situation and decided on an investment based on the customer lifecycle of the product. To summarize, for this scenario and lifecycle-demand curve, the MO model presented the best performance for the service level as it equaled the RP model and had better results in inventory costs compared with both other models while securing a higher service level and higher capacity utilization of the employees as it adapted all areas of inventory management to the customer demand.

\subsection{Discussion}

All scenarios presented one article along its product lifecycle with different additional fluctuations or influences with the exception of the first scenario or base scenario. Based on the presented model, the following scenarios for managers can be classified.

The scenarios depicted in Figure 7 do not consider the external environment, such as the geographical location, or the potential disruptions, such as pandemics, disasters, or economic crises. However, assuming that these external events have the same effect to all four supply chain scenarios, then from the internal point of view, this classification of scenarios provides an indication of the options to be used within the market-oriented procurement model:

1. Existing flow and product: A lower demand uncertainty is expected as well as a low supply uncertainty in comparison to the other scenarios. Historical data are available. The production, storage, and distribution capacities are known as well as the lead times. In this scenario, the EOQ option can be appropriate in case the demand is stationary.

2. New flow and existing product: A lower demand uncertainty is expected with a higher supply uncertainty in comparison to the first scenario. Historical data are available, but the production, storage, and distribution capacities are not known as well as the lead times. In this scenario, the reorder-point option can be appropriate, and monitoring of the capacities and lead times is required.

3. Existing flow and new products: A higher demand uncertainty is expected with a lower supply uncertainty in comparison to the first scenario. Historical data are not available, but the production, storage, and distribution capacities are known as well as the lead times. In this scenario, the reorder-point option can be appropriate, and monitoring of the customer demand is required.

4. New flow and new products: A higher demand uncertainty is expected with a higher supply uncertainty in comparison to all the other scenarios. Historical data are not available, nor are the production, storage, distribution capacities, and lead times. In this scenario, the reorder-point option can be appropriate with monitoring of each stock transaction and with real-time information regarding the customer demand along the supply chain. 


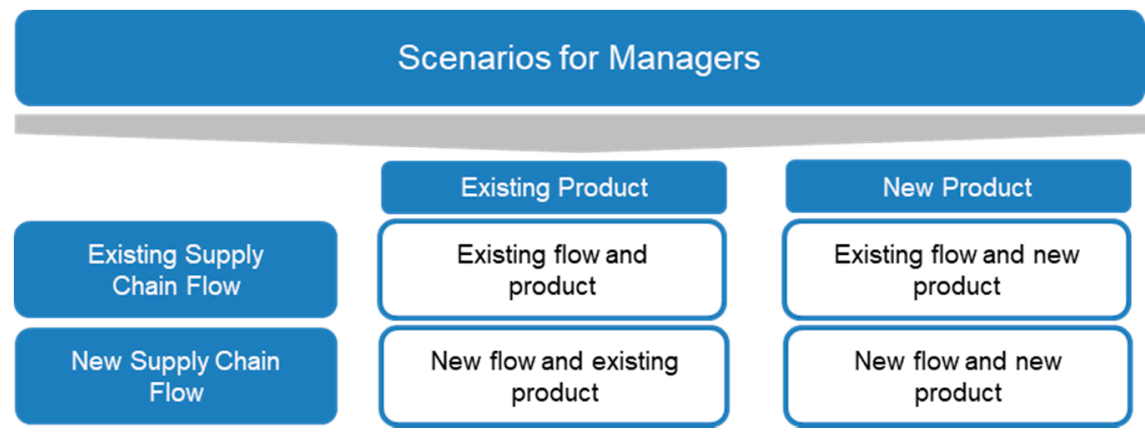

Figure 7. Discussion framework: scenarios for managers (own elaboration).

\section{Conclusions}

After completion of the research work, the following points can be successfully concluded:

- Due to a new conceptual model developed for inventory management, managers can use the model as conceptual guidance or as a tool for improving operations and decision-making by gathering real-time data within the fourth industrial revolution.

- The case study was created and simulated with different simulation models to test their performances with the same KPIs.

- The simulation of the market-oriented simulation model presented better overall results for the relevant key parameters for all five scenarios, particularly in demand scenarios and product lifecycles with high variability, demand pattern changes, and uncertainty.

As a result, the simulation can evolve as a decision-making support tool for managers to analyze what-if-scenarios, to generate digital twin models, and to develop new IT platforms.

The final goal is to transfer this research method to real organizations, applying it in some cases as a guide for inventory management and in scenarios with volatility, such as product launches and new supply chain flow designs.

In detail, the theoretical, managerial, and empirical conclusions, as well as the limitations of the research performed and the potential research work derived, are described as follows:

Theoretical conclusions and contributions-the research paper pursued the following objectives: the development of a model for higher OTD and service levels while optimizing the inventory costs. To achieve these goals, a cybernetic model was applied with the following characteristics:

- Forecasting techniques and their application for different planning horizons. Selection according to the maximization of the forecasting accuracy under demand uncertainty.

- Selection of the safety factor depending on the target service level.

- Use of the different procurement policies and their change based on the system conditions as demand variability.

- Investment decisions are based on product lifecycle.

Therefore, the main theoretical contribution and novelty of the approach is the integrated conceptual model developed with a methodological combination of:

- Decision-making within the model for the planning areas based on real-time data.

- Criteria for changing between forecasting methods.

- Criteria for changing procurement policies.

- Criteria for adapting organizational planning dynamically.

- Consideration of different lifecycle patterns and their consideration of planning and investment decisions.

- Conceptual model based on cybernetics and simulated based on system dynamics. 
Managerial conclusions and contributions:

- The current challenges of manufacturing companies were described, and those influencing the inventory management as well as the common methods were applied in the models.

- Dynamic inventory management with adaptability was proved to be necessary, particularly when uncertainty is high.

- The importance of synchronized demand planning, inventory planning, procurement planning, as well as personal planning together with investment planning, considering the overall lifecycle, was concluded as key for organizations to secure long-term viability.

- The methodological combination provides managers with a framework to be prepared for future scenarios, to generate digital twins, and to develop IT software based on market-oriented procurement planning. Therefore, the model is the basis for a conceptual model to generate value-added solutions based on Industry 4.0 technologies, such as the Internet of things and real data monitoring.

Empirical conclusions and contributions: To prove the utility of the new concept, a simulation for a supply chain of an OEM and a Tier 1 manufacturer was created by including the necessary instruments and developed control systems as well as validation by means of simulation. All models were implemented in Vensim software and simulated to compare the performance in different demand scenarios. The benefits of the change from classical inventory management models to an approach using the market-oriented model are:

- Higher service level;

- Higher delivery reliability;

- Lower inventories costs;

- Higher utilization of available resources;

- Lower forecast error; and

- Lower outsourcing costs for warehouse storage.

The limitations of the research work include:

- We assumed transport and storages only for one product;

- The complexity of the supply chain was partially built in the simulation model;

- The organization structure and interfaces were not considered in the simulation model;

- All information was considered as available; and

- The concept was not proven in any company.

Future research—the potential research derived from this paper includes:

- To transfer this research method to real supply chains, apply it in particular cases as a tool for strategic planning and assist supply chain leaders by centralizing all data related to a topic in a short period of time, enabling the simulation of what-if-scenarios.

- To consider organization units and their communication within the simulation model.

To summarize, our research showed the potential benefits of inventory management based on a continuous feedback control loop in which committed delivery dates can be met as well as improvement in the costs and investment performance indicators leading to an increase in competitiveness.

Author Contributions: Conceptualization, M.G.-G. and S.G.-G.; data curation, S.G.-G.; formal analysis, S.G.-G.; investigation, S.G.-G.; methodology, S.G.-G.; resources, S.G.-G.; software, S.G.-G.; supervision, M.G.-G. and S.G.-G.; validation, S.G.-G.; writing-original draft, S.G.-G. All authors have read and agreed to the published version of the manuscript.

Funding: This research received no external funding.

Conflicts of Interest: The authors declare no conflict of interest. 


\section{Appendix A. Formulae of the Conceptual Model}

- Moving average: The simple moving average (SMA) is the non-weighted mean of the previous $n$ data [42]. In the model, the cumulative moving average (CMA) is applied:

$$
\text { Forecast with } C M A=F_{(t+1)}=\frac{1}{n} \sum_{t=1}^{n} \text { item demand }(t)
$$

with $n=$ number of days; $F_{(t+1)}=$ demand forecast value at time $t+1$.

- Linear regression: The regression method is usually applicable to a steady course of a time series or a stable trend [43]. It can be defined as follows where "a" is the slope, $t_{\text {trend }}$ is the time since the trend demand pattern started, and " $b$ " is the value at the time when the trend demand pattern was initiated:

$$
F_{(t+1)}=a \times t_{\text {trend }}+b .
$$

- Exponential smoothing: The exponential smoothing method carries out an exponential weighting of the forecast errors to determine the forecast value for the next period [42]:

- Exponential smoothing of the first order: based on the literature, the formula used is [43]

$$
\begin{gathered}
F_{(t+1)}=\alpha \times D_{t}+(1-\alpha) \times F_{(t)} . \\
\text { with } \alpha=\text { smoothing parameter. }
\end{gathered}
$$

- Exponential smoothing of the second order: based on the literature, the method developed by Holt is used [42]:

$$
\begin{gathered}
F_{(t+1)}=L_{(t)}+T_{(t)} \\
L_{(t)}=\alpha \times T_{t}+(1-\alpha) \times\left(L_{(t-1)}+T_{(t-1)}\right) \\
T_{(t)}=\beta \times\left(L_{(t)}-L_{(t-1)}\right)+(1-\beta) \times T_{(t-1)}
\end{gathered}
$$

with $\mathrm{L}_{(\mathrm{t})}=$ smoothed value for $t ; T_{(t)}=$ trend estimation for $t$;

$\beta=$ smoothing parameter for the trend estimation.

- Exponential smoothing of the third order: based on the literature, the method developed by Winters is used [43]:

$$
\begin{gathered}
F_{(t+1)}=\left(L_{(t)}+T_{(t)}\right) \times S_{(t+1-s)} \\
L_{(t)}=\alpha \times \frac{Y_{(t)}}{S_{(t-s)}}+(1-\alpha) \times\left(L_{(t-1)}+T_{(t-1)}\right) \\
T_{(t)}=\beta \times\left(L_{(t)}-L_{(t-1)}\right)+(1-\beta) \times T_{(t-1)} \\
S_{(t)}=\gamma \times \frac{Y_{(t)}}{L_{(t)}}+(1-\gamma) \times S_{(t-s)}
\end{gathered}
$$

$\mathrm{S}_{(\mathrm{t})}=$ saisonal estimation for $t+1$;

$\gamma=$ smoothing parameter for trend estimation.

- $\quad$ Croston Method: a method for sporadic demand patterns [42]:

$$
F_{(t+1)}=\frac{F_{(t)}}{E_{(t)}}
$$




$$
\begin{array}{r}
F_{(t)}=F_{(t-1)} \text { if } D_{(t)}=0 ; \text { else } F_{(t)}=\alpha \times D_{(t)}+(1-\alpha) \times F_{(t-1)} \\
E_{(t)}=E_{(t-1)} \text { if } D_{(t)}=0 ; \text { else } E_{(t)}=\alpha \cdot q+(1-\alpha) \times E_{(t-1)}
\end{array}
$$

with $\mathrm{q}=$ periods since demand.

Methods to measure and provide conclusions regarding the accuracy of the used forecast method [46]:

$$
\begin{gathered}
\operatorname{MAD}_{(t)}=\frac{1}{n} * \sum_{t=1}^{n}\left|D_{(t)}-F_{(t)}\right| \\
\operatorname{MSE}_{(t)}=\frac{1}{n} * \sum_{t=1}^{n}\left(D_{(t)}-F_{(t)}\right)^{2} \\
\operatorname{MAPE}_{(t)}=\frac{1}{n} * \sum_{t=1}^{n} \frac{\left|D_{(t)}-F_{(t)}\right|}{D_{(t)}}
\end{gathered}
$$

with

$n=$ number of days;

$D_{(t)}=$ real demand value at time $t$.

$F(t)=$ demand forecast value at time $t$.

The coefficient of variation (CV) is defined as follows [43]:

$$
C V(D)=\frac{\sigma(D)}{\bar{D}}
$$

with:

$\sigma(D)=$ standard deviation of demand $(D)$;

$D=$ arithmetic average of demand.

Reorder Point method and its formulae applied in the conceptual model:

$$
\begin{gathered}
\text { Reorder Point }=s_{(t)}=\text { Base stock }\left[B S_{(t)}\right]+\text { Safety Stock }\left[S S_{(t)}\right] \\
\qquad \begin{array}{c}
S S_{(t)}=f(R T, S L, \text { forecast failure }) \\
=k \times \sqrt{\overline{R T} \cdot \sigma_{(D, t)}^{2}+F_{(t)}^{2} \cdot \sigma_{(R T, t)}^{2}}+\text { Backlogs }
\end{array} \\
B S_{(t)}=f(R T, \text { forecast failure })=\overline{R T} \times \overline{F_{(t)}} \\
\text { Reorder Point }=s_{(t)}=\overline{R T} \times \overline{F_{(t)}}+k \times \sqrt{\overline{R T} \cdot \sigma_{(D, t)}^{2}+F_{(t)}^{2} \cdot \sigma_{(R T, t)}^{2}}+\text { Backlogs } \\
\sigma_{(t)}=1,25 \cdot M A D
\end{gathered}
$$

with $\overline{F_{(t)}}$ as the average demand forecast during the RT.

$$
\begin{aligned}
\text { Target Level }(S) & =2 \times \text { BS }(\text { Base Stock })+\text { SS }(\text { Safety Stock }) \\
& + \text { Customer backlogs }
\end{aligned}
$$


Table A1. Safety factor, k; service level (own elaboration based on [43]).

\begin{tabular}{cc}
\hline Service Level & Safety Factor, k \\
\hline $90 \%$ & 1.28 \\
$95 \%$ & 1.64 \\
$99 \%$ & 2.33 \\
$99.9 \%$ & 3.09 \\
\hline
\end{tabular}

Calculation of the EOQ with backordering allowed [49]:

$$
E O Q_{\text {Backordering }}[\text { Units }]=Q_{E} \times Q_{B}=\sqrt{\frac{2 \times A \times S}{I \times C}} \times \sqrt{\frac{I \times C+\pi}{\pi}}
$$

with $Q_{E}=$ classic EOQ; $Q_{B}=$ factor when allowing backordering; $A=$ annual demand (Units/Year); $S=$ procurement cost per order (USD); $C=$ cost per unit depending on the batch size (USD/Unit); $\mathrm{I}=$ inventory holding costs (1/Year); and $\pi=$ backordering costs (USD/Unit).

\section{Appendix B. Formulae of Key Performance Indicators (KPIs)}

Parameters referring to a specific scenario are those that define the scenario itself and are exogenous variables:

- Cumulated Demand (products): This represents the cumulated demand to be satisfied in a certain period:

$$
\text { Cumulated Demand (products) }=\sum_{t=1}^{n} \text { Demand at time period } t \text {. }
$$

System efficiency indicators refer to the efficiency parameters that are needed to reach the required satisfaction rate and service level:

- MAD of the forecast (products): This is the sum of the absolute values that come from the difference between the real and forecast demands for the simulation periods [42]. This sums the values of the forecast errors and divides the sum by the number of periods. MAD is a useful method to show the forecast error in the same units of the time series data [42]. In the model, the weekly production order is leveled based on a monthly forecast and used to place production orders:

$$
M A D \text { forecast production order (products) }=\frac{\sum_{t=1}^{n}|D(t)-F(t)|}{\sum_{t=1}^{n} t}
$$

- Average WIP stock (products): This is the average stock after production until the end-customer. Inventory is also one of the most important drivers in a distribution network [51]. Inventory always involves storage costs; therefore, stock levels should be minimized while assuring the service level that was established for the customers in the strategy of the company:

$$
\varnothing \text { Average WIP stock (products) }=\frac{\sum_{t=1}^{n} \text { Stock at the warehouses at time } t}{\sum_{t=1}^{n} t}
$$

- Average stock at Tier 1 producer and at original equipment manufacturer (OEM) producer (products): This applies the same formula as for the average WIP stock when considering only the specific warehouses of Tier 1 or OEM producers.

- Utilization rate of employees (\%): This is the percentage of the nominal capacity of the employees that is used to perform the warehouse activities. Utilization is another important KPI. It defines 
the rate of capacity that is currently being used [51]. In this case, it defines the capacity utilization of those employees that perform the warehouse activities:

$$
\begin{aligned}
& \text { Utilization rate of employees }(\%)=\frac{\sum_{t=1}^{n} \text { Capacity used }}{\sum_{t=1}^{n} \text { Nominal Capacity }} \times 100 \% \\
& \qquad=\frac{\sum_{t=1}^{n} \text { Capacity used }}{\sum_{t=1}^{n}(\text { Capacity per employee } * \text { Number of employees })} \times 100 \%
\end{aligned}
$$

- On-time delivery (OTD) (\%): This represents the percentage of the quantity delivered on time for a certain period. It is a quantity-oriented KPI that describes the customer demand percentages that could be satisfied directly from the stock in a certain period [42]. The difference with the service level (\%) relapse is in consideration of the single product and not on the whole demand to meet in each week:

$$
\text { OTD }(\%)=\frac{\sum_{t=1}^{n} \text { Products delivered on time }}{\sum_{t=1}^{n} \text { Total products ordered }} \times 100 \% \text {. }
$$

- Service level (\%): This represents the percentage of weeks in which the demand is satisfied. It is the probability of demand fulfillment in a certain period with the stock in the warehouses. It also considers the accumulated backlog. Therefore, it is a quantity- and time-oriented KPI [42]. It represents the percentage of weeks in which the clients were fully served with all the products they ordered. It is considered as an unmet demand in those cases when the delivered quantity to the customers was not sufficient to supply the customer demand for the current period and the customer's backlog from previous weeks:

$$
\text { Service Level }(\%)=\frac{\sum_{t=1}^{n} \text { Weeks without product backlog }}{\sum_{t=1}^{n} t} \times 100 \% .
$$

- Average procurement quantity (products): This represents the average quantity ordered along a certain period:

$$
\begin{aligned}
& \varnothing \text { Average Proc. Quantity }(\%) \\
& \qquad=\frac{\sum_{t=1}^{n} \text { Procurement Quantity }}{\sum_{t=1}^{n} \text { Procurement orders placed until time }} \times 100 \% .
\end{aligned}
$$

- Average customer backlog (products): This is the sum of all products until the current period that were not delivered to meet the delivery date and, therefore, that is going to be served with delay:

$$
\varnothing \text { Average customer backlog (products) }=\frac{\sum_{t=1}^{n} \text { Customer backlog (products) }}{\sum_{t=1}^{n} t}
$$

- Weeks with customer backlog (weeks): This is the sum of all weeks until the current period in which a client was not fully served:

$$
\text { Cumulated Customer backlog (weeks) }=\sum_{\mathrm{t}=1}^{\mathrm{n}} \text { Customer backlog (weeks). }
$$

Economic parameters refer to the investment and cost indicators to be considered in the procurement model for the OEM manufacturer that must procure and place the orders to the Tier 1 supplier: 
- Inventory costs (million USD): This is the sum of the procurement costs from an external supplier or from in-house production, storage costs, material planning, and handling costs [43]:

$$
\begin{aligned}
& \text { Inventory Costs (mill.USD) } \\
& \qquad \begin{array}{l}
\quad \sum_{t=1}^{n} \text { Procurement costs }+ \text { Warehouse Storage costs } \\
+ \text { Stockout cost }
\end{array}
\end{aligned}
$$

- Procurement costs (million USD): In the model, this is applied as external procurement costs and not as in-house production. Therefore, the external procurement costs depend on the order quantity and cost price as direct costs and the order costs and cost rate of the order initiations [43]:

$$
\begin{aligned}
& \text { Procurement costs (mill. USD) } \\
& \qquad=\sum_{t=1}^{n} \text { Units } \times \text { Cost per Unit }+ \text { Orders } \times \text { Cost per Order }
\end{aligned}
$$

- Warehouse storage costs (million USD): This is the sum of capital commitment costs and storage costs [43]:

- Capital commitment costs: This is the function of the interest rate, inventory quantity, and its inventory value and storage time:

$$
\begin{aligned}
& \text { Capital commitment costs (mill. USD) } \\
& \qquad=\sum_{t=1}^{n} \text { Inventory value } \times \text { Storage time } \times \text { Interest rate. }
\end{aligned}
$$

- Storage costs: These are determined by the space, personnel, handling, and depreciation costs. The model does not include the renting of spaces or depreciation costs:

$$
\text { Storage costs (mill. USD) }=\sum_{t=1}^{n} \text { Personnel costs }
$$

- Stock-out or shortage costs: The components of shortage costs are lost contribution margins, reduced revenues, and additional costs, such as contractual penalties [43]. For the model, it is considered as a penalty per unit not delivered on time in each period:

$$
\begin{aligned}
& \text { Shortage costs (mill. USD) } \\
& \qquad=\sum_{t=1}^{n} \text { Penalty per unit backlogged } \times \text { units backlogged. }
\end{aligned}
$$

- Investment costs (million USD): This is the quantity invested in new warehouses or in an increase in capacity along the supply chain:

$$
\text { Investment costs (mill. USD) }=\sum_{t=1}^{n} \text { Investment per time period. }
$$

\section{References}

1. Bonney, M.; Jaber, M.Y. Environmentally responsible inventory models: Non-classical models for a non-classical era. Int. J. Prod. Econ. 2011, 133, 43-53. [CrossRef]

2. Harris, F.W. How many parts to make at once. Oper. Res. 1990, 38, 947-950. [CrossRef] 
3. Syntetos, A.A.; Boylan, J.E.; Disney, S.M. Forecasting for inventory planning: A 50-year review. J. Oper. Res. Soc. 2009, 60 (Suppl. 1), S149-S160. [CrossRef]

4. Ashayeri, J.; Heuts, R.J.M.; Lansdaal, H.G.L.; Strijbosch, L.W.G. Cyclic production-inventory planning and control in the pre-Deco industry: A case study. Int. J. Prod. Econ. 2006, 103, 715-725. [CrossRef]

5. Bonney, M.C. Trends in inventory management. Int. J. Prod. Econ. 1994, 35, 107-114. [CrossRef]

6. Guchhait, P.; Maiti, M.K.; Maiti, M. Production-inventory models for a damageable item with variable demands and inventory costs in an imperfect production process. Int. J. Prod. Econ. 2013, 144, 180-188. [CrossRef]

7. Kilic, O.A.; Tarim, S.A. An investigation of setup instability in non-stationary stochastic inventory systems. Int. J. Prod. Econ. 2011, 133, 286-292. [CrossRef]

8. Mula, J.; Poler, R.; García-Sabater, J.P.; Lario, F.C. Models for production planning under uncertainty: A review. Int. J. Prod. Econ. 2006, 103, 271-285. [CrossRef]

9. Chowdhury, M.T.; Sarkar, A.; Paul, S.K.; Moktadir, M.A. A case study on strategies to deal with the impacts of COVID-19 pandemic in the food and beverage industry. Oper. Manag. Res. 2020,1-13. [CrossRef]

10. Leite, H.; Lindsay, C.; Kumar, M. COVID-19 outbreak: Implications on healthcare operations. TQM J. 2020. [CrossRef]

11. Shen, W.; Yang, C.; Gao, L. Address business crisis caused by COVID-19 with collaborative intelligent manufacturing technologies. IET Collab. Intell. Manuf. 2020, 2, 96-99. [CrossRef]

12. Dmitry, I.; Dolgui, A. A digital supply chain twin for managing the disruption risks and resilience in the era of Industry 4.0. Prod. Plan. Control. 2020, 1-14. [CrossRef]

13. Butt, J. A Strategic Roadmap for the Manufacturing Industry to Implement Industry 4.0. Designs 2020, 4, 11. [CrossRef]

14. Whybark, D.C. Issues in managing disaster relief inventories. Int. J. Prod. Econ. 2007, 108, 228-235. [CrossRef]

15. Strina, G. Zur messbarkeit Nicht-Quantitativer Größen im Rahmen Unternehmenskybernetischer Prozesse; Aachen, Technische Hochschule, Habil: Aachen, Germany, 2005.

16. Ashby, W.R. An Introduction to Cybernetics; William Clowes and sons: London, UK, 1957.

17. Groten, M. Integrierte Planung von Distributionsnetzwerken auf Basis des Viable-System-Models; Apprimus Verlag: Aachen, Germany, 2017.

18. Beer, S. Brain of the Firm: A Development in Management Cybernetics Herder and Herder; Verlag Herder: Freiburg im Breisgau, Germany, 1972.

19. Heylighen, F.; Joslyn, C. Cybernetics and second order cybernetics. Encycl. Phys. Sci. Technol. 2001, 4, 155-170.

20. Komus, A.; Wauch, F. Wikimanagement: Was Unternehmen von Social Software und Web 2.0 lernen können; Oldenbourg Verlag: Munich, Germany, 2009.

21. Feldmann, K.; Schmuck, T.M. Distributionsprozesse elektronischer konsumgüter: Modellierung unter verwendung von referenzbausteinen für die ablaufsimulation. ZWF Z. Für Wirtsch. Fabr. 2007, 102, 869-874. [CrossRef]

22. Campuzano, F.; Bru, J.M. Supply Chain Simulation: A System Dynamics Approach for Improving Performance; Springer Science \& Business Media: Berlin/Heidelberg, Germany, 2011.

23. Chang, Y.; Makatsoris, H. Supply chain modeling using simulation. Int. J. Simul. 2001, 2, 24-30.

24. Arnold, D.; Furmans, K. Materialfluss in Logistiksystemen; Springer: Berlin/Heidelberg, Germany, 2005; Volume 6.

25. Filippov, A.; Borshchev, A. From System Dynamics and Discrete Event to Practical Agent Based Modeling: Reasons, Techniques, Tools; St. Petersburg Technical University: Saint Petersburg, Russia, 2004.

26. März, L.; Krug, W.; Rose, O.; Weigert, G. Simulation und Optimierung in Produktion und Logistik: Praxisorientierter Leitfaden mit Fallbeispielen; Springer: Berlin/Heidelberg, Germany, 2011.

27. Schröter, M. Strategisches Ersatzteilmanagement in Closed-Loop Supply Chains; Deutscher Universitäts-Verlag: Wiesbaden, Germany, 2006.

28. Akkermans, H.; Dellaert, N. The rediscovery of industrial dynamics: The contribution of system dynamics to supply chain management in a dynamic and fragmented world. Syst. Dyn. Rev. 2005, 21, 173-186. [CrossRef]

29. Angerhofer, B.J.; Angelides, M.C. System dynamics modelling in supply chain management: Research review. In Proceedings of the 2000 Winter Simulation Conference Proceedings, Orlando, FL, USA, 10-13 December 2000; Volume 1, pp. 342-351.

30. Reggelin, T. Schneller Entscheiden; Log.Kompass; DVV Media Group: Hamburg, Germany, 2012.

31. Tziourtzioumis, C. Inventory Policies in Continuous Review Systems: Evaluation and Estimation

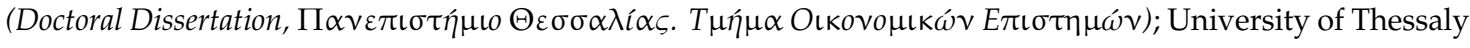
Institutional Repository: Thessaly, Greece, 2016.

32. Garcia-Herreros, P.; Agarwal, A.; Wassick, J.M.; Grossmann, I.E. Optimizing inventory policies in process networks under uncertainty. Comput. Chem. Eng. 2016, 92, 256-272. [CrossRef] 
33. Mahamani, A.; Rao, K.P.; Pandurangadu, V. Evaluation of a (R, Q, K, T) Single Item Inventory Replenishment Policy Through Excel Spread Sheet Simulation in Supply Chain. Ind. Eng. J. 2017. [CrossRef]

34. de Melo, Á.S. A Machine Learning Approach to the Optimization of Inventory MANAGEMENT Policies; Faculdade de engenharia da universidade do porto: Porto, Portugal, 2019.

35. Tao, F.; Fan, T.; Wang, Y.Y.; Lai, K.K. Joint pricing and inventory strategies in a supply chain subject to inventory inaccuracy. Int. J. Prod. Res. 2019, 57, 2695-2714. [CrossRef]

36. Brown, R.G.; Easterfield, T.E. A proposed definition of operations research. J. Oper. Res. Soc. 1951, 2, 21-24. [CrossRef]

37. Schwaninger, M. Systemtheorie: Eine Einführung für Führungskräfte, Wirtschafts-und Sozialwissenschaftler, Diskussionsbeitrag Nr. 19; Institut für Betriebswirtschaft der Universität St.: Sankt Gallen, Switzerland, 2004.

38. Auerbach, T.; Bauhoff, F.; Beckers, M.; Behnen, D.; Brecher, C.; Brosze, T.; Esser, M. Selbstoptimierende Produktionssysteme. In Integrative Produktionstechnik für Hochlohnländer; Springer: Berlin/Heidelberg, Germany, 2011; pp. 747-1057.

39. Waller, M.A.; Dabholkar, P.A.; Gentry, J.J. Postponement, product customization, and market-oriented supply chain management. J. Bus. Logist. 2000, 21, 133-160.

40. Kletti, J.; Schumacher, J. Die Perfekte Produktion (Perfect Manufacturing); Springer: Berlin/Heidelberg, Germany, 2011.

41. Stadtler, H.; Kilger, C. Supply Chain Management and Advanced Planning; Springer: Berlin/Heidelberg, Germany, 2002.

42. Schuh, G.; Stich, V.; Wienholdt, H. Logistikmanagement.; Springer: Berlin/Heidelberg, Germany, 2013.

43. Meyer, J.C.; Sander, U.; Wetzchewald, P. Bestände Senken, Lieferservice Steigern-Ansatzpunkt Bestandsmanagement; FIR: Aachen, Germany, 2019.

44. Schuh, G.; Schmidt, C. Produktionsmanagement; Springer: Berlin/Heidelberg, Germany, 2014.

45. Gallego-García, S.; Reschke, J.; García-García, M. Design and simulation of a capacity management model using a digital twin approach based on the viable system model: Case study of an automotive plant. Appl. Sci. 2019, 9, 5567. [CrossRef]

46. Schönsleben, P. Integrales Logistikmanagement: Operations und Supply Chain Management Innerhalb des Unternehmens und Unternehmensübergreifend; Springer: Berlin/Heidelberg, Germany, 2011.

47. Sebastian, H.J. Optimierung von Distributionsnetzwerken. In BoD-Books on Demand; EAGLE: Leipzig, Germany, 2013.

48. Grün, O.; Jammernegg, W. Grundzüge der Beschaffung, Produktion und Logistik Pearson Deutschland GmbH; Pearson: Munich, Germany, 2009.

49. De Kok, T.; Inderfurth, K. Nervousness in inventory management: Comparison of basic control rules. Eur. J. Oper. Res. 1997, 103, 55-82. [CrossRef]

50. Muckstadt, J.A.; Sapra, A. Principles of Inventory Management: When You Are down to Four, Order More; Springer Science \& Business Media: New York, NY, USA, 2010.

51. Chopra, S.; Meindl, P. Supply chain management. Strategy, planning \& operation. In Das Summa Summarum des Management; Gabler: Wiesbaden, Germany, 2007; pp. 265-275.

52. Sabadka, D. Impacts of shortening product life cycle in the automotive industry. Transf. Inovácií 2013, 29, 251-253.

53. Lešková, A. Logistics Concept of Supply Chain in Automotive Production. 2012. Available online: http://web2.vslg.cz/fotogalerie/acta_logistica/2012/3-cislo/4_leskova.pdf (accessed on 1 July 2018).

54. Sterman, J.D. Business Dynamics: Systems Thinking and Modeling for a Complex World; Irwin/McGraw-Hill: New York, NY, USA, 2000.

55. Wensing, T. Periodic Review Inventory Systems 123; Springer: Berlin/Heidelberg, Germany, 2011.

56. Cox, W.E. Product life cycles as marketing models. J. Bus. 1967, 40, 375-384. [CrossRef]

57. Rink, D.R.; Swan, J.E. Product life cycle research: A literature review. J. Bus. Res. 1979, 7, 219-242. [CrossRef]

Publisher's Note: MDPI stays neutral with regard to jurisdictional claims in published maps and institutional affiliations. 